\author{
ARTIGO \\ d० https://doi.org/10.22481/praxisedu.v16i41.6480
}

\title{
MAPEAMENTO DE ESTUDOS SOBRE DEFICIÊNCIA INTELECTUAL, ALFABETIZAÇÃO E TECNOLOGIA: ESTADO DA QUESTÃO
}

\author{
MAPPING OF STUDIES ON INTELLECTUAL DISABILITY, LITERACY AND
}

TECHNOLOGY: STATE OF THE QUESTION

\section{MAPEO DE ESTUDIOS SOBRE DISCAPACIDAD INTELECTUAL, ALFABETIZACIÓN Y TECNOLOGÍA: ESTADO DE LA PREGUNTA}

\author{
Camila Almada Nunes \\ Universidade Federal do Ceará - Brasil \\ Francisca Geny Lustosa \\ Universidade Federal do Ceará - Brasil
}

\begin{abstract}
Resumo: O presente artigo apresenta a elaboração do Estado da Questão (EQ) relativa à temática do uso de aplicativos de leitura e escrita na alfabetização e letramento de crianças com deficiência intelectual, na área da Educação. Para tanto procedemos ao levantamento de estudos nacionais e internacionais em periódicos, indexados pela Coordenação de Aperfeiçoamento de Pessoal de Nível Superior (CAPES) e nos Anais das Reuniões Anuais da Associação Nacional de Pós-Graduação e Pesquisa em Educação (ANPEd). O mergulho na literatura mapeada propiciou a oportunidade de referenciar relevante e extensiva quantidade de publicações articuladas ao tema ora investigado. Os resultados mostram que do total de 1644 (100\%) estudos consultados, $78(4,7 \%)$ apresentaram proximidade com o nosso objeto investigado, abordando as temáticas de deficiência intelectual, alfabetização e letramento, tecnologia e/ou aplicativos e revelando o interesse dos pesquisadores por esses enfoques. Também notamos que, em geral, foram poucos os trabalhos que interligaram especificamente as tecnologias às deficiências e/ou transtornos, mais raros ainda aqueles que operaram com dispositivos móveis e aplicativos. Desse modo, a busca por desvelar o tema em questão, fez emergir um campo profícuo para os mais diversos trabalhos/artigos, fazendo-nos enveredar por áreas transversais e interdisciplinares, de modo a evitar vieses na conceituação de categorias teórico-empíricas e definição dos referenciais. Portanto, esse exercício tornou-se primordial para conhecer "o que foi" e "o que está sendo" produzido pelos estudiosos nessa área específica de pesquisa.
\end{abstract}

Palavras chave: Deficiência intelectual; Alfabetização; Tecnologia.

\begin{abstract}
This article presents the elaboration of the State of the question (EQ) on the theme of using reading and writing applications in the literacy and literacy of children with intellectual disabilities, in the area of Education. For this, we proceeded to the survey of national and international studies was carried out in magazines, indexed by the Coordination for the Improvement of Higher Education Personnel (CAPES) and in the annals of the National Association of Graduate Studies and Research in Education (ANPEd).The immersion in assigned literature provided an opportunity to refer to a relevant and extensive number of published productions articulated on the subject under investigation. Of the
\end{abstract}


total of 1644 (100\%) studies consulted, 78 (4.7\%) showed evidence of proximity to our research object, addressing the themes of intellectual disability, literacy and literacy, technology and/or applications and revealing the interest of researchers in these approaches. We also noticed that, in general, there were few works that linked technologies to deficiencies and or disorders, even rarer those that operated with mobile devices and apps. In this way, the search to unveil the theme in question has emerged a fruitful field for the most diverse papers/articles, to embark transversal and interdisciplinary areas, in order to avoid bias in the conceptualization of theoretical-empirical categories and definition of references. Therefore, this exercise became essential to know 'what was' and 'what is being' produced by academics in this specific area of research.

Keywords: Intellectual disability; Literacy; Technology.

Resumen: Este artículo presenta la descripción del proceso de elaboración del Estado de la pregunta (EQ) sobre el tema del uso de aplicaciones de lectura y escritura en la alfabetización y alfabetización de niños con discapacidades intelectuales, en el área de Educación. Para ello, encuestamos estudios nacionales e internacionales en revistas, indexadas por el Coordinador del Personal de Educación Superior (CAPES) y en las actas de la Asociación Nacional de Estudios y Estudios de Investigación (ANPEd). La inmersión en la literatura asignada brindó la oportunidad de referirse a un número relevante y extensa de producciones publicadas articuladas al tema investigado. Del total de 1644 (100\%) estudios consultados, 78 (4.7\%) mostraron evidencia de proximidad a nuestro objeto de investigación, abordando los temas de discapacidad intelectual, alfabetización y alfabetización, tecnología y/o aplicaciones y revelando el interés de investigadores por estos enfoques. También notamos que, en general, había pocos trabajos que vincularan específicamente las tecnologías con deficiencias y trastornos, más raros aquellos que operaban con dispositivos móviles y aplicaciones. De esta forma, la búsqueda para desvelar el tema en cuestión ha surgido como un campo fructífero para los más diversos trabajos/artículos, embarcarse en áreas transversales e interdisciplinarias, para evitar sesgos en la conceptualización de categorías teórico-empíricas y definición de referencias. Por lo tanto, este ejercicio se convirtió esencial para saber 'lo qué fue' y 'lo qué se está' producido por académicos en esta área específica de investigación.

Palabras clave: Discapacidad intelectual; Alfabetización; Tecnología.

\section{Introdução}

Este estudo apresenta a construção do Estado da Questão (EQ) sobre "o uso de aplicativos de leitura e escrita na alfabetização e letramento de crianças com deficiência intelectual". Elaborar o EQ nos permite um rigoroso mergulho bibliográfico para desvelar a conjuntura atual na ciência do tema ora investigado. Para tanto, faz-se uma maneira peculiar de articular e evidenciar diversas investigações, bem como distintas proposições e interesses de pesquisa. Por sua vez, em trabalhos acadêmicos, construir o EQ tem a finalidade de anunciar a contribuição epistêmica pretendida com o estudo em desenvolvimento, a fim de formular "sua percepção original da questão ou da problemática em foco, desvelando o horizonte que pretende atingir" (NÓBREGA-THERRIEN; THERRIEN, 2004, p.12). 
Deste modo, destacamos nesse artigo, que nossas primeiras aproximações com os subsídios teórico-metodológicos de elaboração do EQ advieram dos estudos durante o curso de mestrado, em que, na ocasião, tivemos a oportunidade de construir o inventariado do tema de pesquisa e ampliar o entendimento sobre as formas de mapear e descrever produções científicas disponíveis em bases de dados. Nesse sentido, não somos inexperientes no assunto ao afirmar que, para além das habilidades e competências do pesquisador em compor uma sequência lógica de argumentos fundamentados, é preciso se apropriar dos achados e revelar autoria própria no texto e nas compreensões resultantes.

Destarte, assinalamos que constantemente nos deparamos com equívocos conceituais entre estado da arte, estado da questão e revisão de literatura. Por conseguinte, julgamos válido o esclarecimento dos três conceitos respaldados pelos referenciais de especialistas dessa temática/área. Nóbrega-Therrien e Therrien (2010) asseguram que o estado da arte expressa uma metodologia de cunho inventariante e descritivo de estudos acadêmicos e científicos sobre determinado tema em investigação, não há um diálogo ou análise crítica relacionada com o trabalho investigativo do pesquisador. Enquanto no estado da questão, se articulam os achados com as particularidades do seu tema e define claramente a contribuição autêntica da sua investigação para o campo científico. Já a revisão de literatura "se apresenta como um encadeamento de categorias teóricas do trabalho, didaticamente organizadas e sintetizando autores de referência" (p. 36).

Importa ainda salientar que o EQ subsidia e perpassa todas as etapas do estudo acadêmico, contribui na definição dos objetivos, auxilia no planejamento metodológico, propicia a identificação de categorias teóricas que constituem o argumento para as discussões e análises de dados, além disso, manifesta de forma clara ou inexplícita, na conclusão, o diferencial da investigação para o campo do conhecimento científico; de posse dessa compreensão sobre a relevância de realização do EQ para todo pesquisador no decurso do trabalho investigativo, socializamos, neste artigo, a descrição desse processo de construção que realizamos mais recentemente como base para nossa investigação em nível de Doutorado ${ }^{1}$, em curso, na área da Educação. Além do importante mapeamento resultante desse levantamento que compõe o EQ no tema abordado, sobressai nessa escrita, as etapas imprescindíveis para sua realização, na divulgação do caminho que trilhamos e que tem como título "aplicativos

\footnotetext{
${ }^{1}$ Pesquisa de doutorado de Camila Almada Nunes sob a orientação da Dra. Francisca Geny Lustosa, em curso, no Programa de Pós-Graduação em Educação, na Universidade Federal do Ceará (UFC) iniciada em agosto de 2018 com previsão de término para julho de 2022.
} 
educacionais de leitura e escrita: implicações na alfabetização e letramento de crianças com deficiência intelectual"

Assim sendo, organizamos o texto em três tópicos: no primeiro, evidenciamos os caminhos trilhados para o mapeamento de busca de dados nos periódicos nacionais e internacionais; no segundo, trazemos o levantamento em periódicos específicos nacionais da área de educação especial; no terceiro, apresentamos os trabalhos publicados e mapeados nas Reuniões Anuais da ANPEd; e, por último, no quarto tópico finalizamos com a análise do que foi encontrado e sua relação com a investigação em desenvolvimento.

\section{Caminhos percorridos na busca e mapeamento de estudos nacionais e internacionais sobre o tema de investigação}

O processo de busca inicial em periódicos, indexados pela Capes foi realizado por meio da base de dados SciELO, que abrange periódicos científicos do Brasil, Chile, Argentina, México, Espanha, Portugal e de outros países da América Latina e África. Dessa forma, para localizar e categorizar as publicações, utilizamos os seguintes descritores para busca: deficiência intelectual, alfabetização e letramento, aplicativo e tecnologia móvel. A escolha por essas palavras-chave evidenciou um panorama diversificado de estudos relacionados ao tema de investigação, conforme ilustrado a seguir:

\begin{tabular}{ccc} 
Descritor & $\begin{array}{c}\text { Quantitativo de } \\
\text { publicações }\end{array}$ & $\begin{array}{c}\text { Publicações com indícios de } \\
\text { proximidade sobre o tema }\end{array}$ \\
\hline Deficiência intelectual & 252 & 21 \\
Alfabetização e letramento & 141 & 13 \\
Aplicativo & 337 & 05 \\
Tecnologia móvel & 67 & 05 \\
Total & 797 & 44 \\
\hline
\end{tabular}

Fonte: Dados coletados entre agosto de 2018 e julho de 2019, todavia atualizados em março de 2020.

Como forma de sistematizar e organizar os resultados encontrados nas publicações consultadas, apresentamos o Quadro 1, a seguir que identifica o primeiro descritor "deficiência intelectual" com os respectivos autores, ano e título dos estudos mapeados. Todavia, destacamos que não foi estabelecido um período temporal para a busca, portanto, o interstício apresentado refere-se ao universo total de publicações disponíveis na plataforma. 
Quadro 1: Levantamento de artigos publicados sobre a deficiência intelectual em periódicos nacionais e internacionais na base de dados SciELO.

\begin{tabular}{|c|c|}
\hline Autor(es)/ Ano & Título \\
\hline $\begin{array}{l}\text { 1. Pedraza Medina; Acle } \\
\text { Tomasini (2009) }\end{array}$ & $\begin{array}{l}\text { Formas de interacción y diálogo maestro-alumno con discapacidad } \\
\text { intelectual en clases de español }\end{array}$ \\
\hline 2. $\quad$ Abdelhameed (2010) & $\begin{array}{l}\text { The development and provision of educational services for children with } \\
\text { intellectual disabilities in Egypt }\end{array}$ \\
\hline 3. Hein et al. (2010) & $\begin{array}{l}\text { Avaliação da eficácia do software "alfabetização fônica" para alunos com } \\
\text { deficiência mental }\end{array}$ \\
\hline $\begin{array}{l}\text { 4. Bezerra; } \\
\text { (2011) }\end{array}$ & $\begin{array}{l}\text { De volta à teoria da curvatura da vara: a deficiência intelectual na escola } \\
\text { inclusiva }\end{array}$ \\
\hline $\begin{array}{ll}\text { 5. } & \begin{array}{l}\text { Rossato; Leonardo } \\
(2011)\end{array}\end{array}$ & $\begin{array}{l}\text { A deficiência intelectual na concepção de educadores da educação especial: } \\
\text { contribuições da psicologia histórico cultural }\end{array}$ \\
\hline 6. Santos (2012) & $\begin{array}{l}\text { Potenciais dificuldades e facilidades na educação de alunos com deficiência } \\
\text { intelectual }\end{array}$ \\
\hline $\begin{array}{l}\text { 7. Toledo; } \\
\text { (2012) }\end{array}$ & $\begin{array}{l}\text { Formação de professores por meio de pesquisa colaborativa com vistas à } \\
\text { inclusão de alunos com deficiência intelectual }\end{array}$ \\
\hline $\begin{array}{l}\text { 8. Lopes; Marquezine } \\
(2012)\end{array}$ & $\begin{array}{l}\text { ocesso de inclusão do aluno com deficiência intelectual } \\
\text { fessores }\end{array}$ \\
\hline $\begin{array}{l}\text { 9. Sanches-Ferreira; } \\
\text { Lopes-dos-Santos; } \\
\text { Santos (2012) }\end{array}$ & $\begin{array}{l}\text { A desconstrução do conceito de deficiência mental e a construção do conceito } \\
\text { de incapacidade intelectual: de uma perspectiva estática a uma perspectiva } \\
\text { dinâmica da funcionalidade }\end{array}$ \\
\hline $\begin{array}{l}\text { 10. Benitez; Domeniconi } \\
\text { (2012) }\end{array}$ & $\begin{array}{l}\text { niliares durante aprendiz } \\
\text { is. }\end{array}$ \\
\hline 11. Pedro; Chacon (2013) & $\begin{array}{l}\text { Softwares educativos para alunos com deficiência intelectual: estratégias } \\
\text { utilizadas }\end{array}$ \\
\hline $\begin{array}{l}\text { 12. Rossato; Constantino; } \\
\text { Mello (2013) }\end{array}$ & $\begin{array}{l}\text { O ensino da escrita e o desenvolvimento das pessoas com deficiência } \\
\text { intelectual }\end{array}$ \\
\hline $\begin{array}{l}\text { 13. Araújo; Almeida } \\
(2014)\end{array}$ & $\begin{array}{l}\text { Contribuições da consultoria colaborativa para a inclusão de pessoas com } \\
\text { deficiência intelectual }\end{array}$ \\
\hline $\begin{array}{l}\text { 14. Leonel; } \\
\text { (2014) }\end{array}$ & $\begin{array}{l}\text { Concepções de professores da educação especial (APAEs) sobre a } \\
\text { aprendizagem e desenvolvimento do aluno com deficiência intelectual: um } \\
\text { estudo a partir da teoria vigotskiana }\end{array}$ \\
\hline $\begin{array}{l}\text { 15. Anache; } \\
\text { (2016) }\end{array}$ & $\begin{array}{l}\text { Caracterização da avaliação da aprendizagem nas salas de recursos } \\
\text { multifuncionais para alunos com deficiência intelectual }\end{array}$ \\
\hline $\begin{array}{l}\text { 16. Schipper; } \\
\text { (2016) }\end{array}$ & $\begin{array}{l}\text { Características do raciocínio do aluno deficiente intelectual à luz da } \\
\text { epistemologia genética }\end{array}$ \\
\hline $\begin{array}{l}\text { 17. Haquin; Cornejo; } \\
\text { Molina (2016) }\end{array}$ & $\begin{array}{l}\text { Adaptaciones metodológicas para el análisis del discurso de niños con } \\
\text { discapacidad intelectual: narrando sin lenguaje }\end{array}$ \\
\hline 18. Videa (2016) & Comprendiendo la discapacidad intelectual: datos, criterios y reflexiones \\
\hline $\begin{array}{l}\text { 19. Maturana; Mendes } \\
\text { (2017) }\end{array}$ & $\begin{array}{l}\text { Inclusão e deficiência intelectual: escola especial e comum sob a óptica dos } \\
\text { próprios alunos }\end{array}$ \\
\hline 20. Vives et al. (2017) & $\begin{array}{l}\text { ¿Cómo fomentar la integración de niños con discapacidad intelectual a } \\
\text { través del juego? Diseño de un kit }\end{array}$ \\
\hline 21. Bezerra (2017) & $\begin{array}{l}\text { Mediação verbal para alunos com deficiência intelectual na sala de recursos } \\
\text { multifuncionais: reflexões e (pro)posições }\end{array}$ \\
\hline
\end{tabular}

Fonte: Elaboração das pesquisadoras.

Dentre as 21 publicações em periódicos (nacionais e internacionais) listadas no quadro, pontuamos que 8 (oito) versam mais diretamente sobre a aprendizagem das crianças com 
deficiência intelectual. Com destaque, as pesquisas trazem considerações sobre as baixas expectativas e concepções dos professores em relação ao aprendizado escolar dos alunos, em geral, baseados na incapacidade dos sujeitos com deficiência intelectual para apropriarem-se dos conhecimentos científicos. No caso, há um descrédito para as possibilidades de aprendizagem desses estudantes. Esse fenômeno é anunciado no estudo de Rossato e Leonardo (2011), constante no item 5 da tabela, quando indicam um processo de naturalização do não aprender, haja vista o que as educadoras investigadas conjecturavam quanto as não-capacidades no âmbito da deficiência intelectual dos seus estudantes.

Leonel e Leonardo (2014), também trazem uma discussão acerca das concepções de professores que atuam na educação especial com o propósito de averiguar como estes compreendem o processo de aprendizagem e desenvolvimento de sujeitos com deficiência intelectual. Para esse estudo realizaram entrevistas com oito docentes e constaram que a maioria delas conferiam as dificuldades de aprendizagem aos próprios alunos, uma vez que em suas percepções a mediação docente não se apresentava como relevante para o desenvolvimento dos alunos com deficiência intelectual, mas sim as práticas focalizadas no concreto, na oralidade e no cotidiano. Em suma, é notório que ainda há uma visão equivocada em relação às potencialidades dos sujeitos com deficiência intelectual, decorrentes da ausência de mediações pedagógicas para favorecer o desenvolvimento das funções psicológicas superiores.

Em contrapartida, Rossato, Constantino e Mello (2013) apresentam uma reflexão teórica acerca do desenvolvimento das crianças com deficiência intelectual e da importância de uma intervenção intencional por parte do professor no processo de aprendizagem, com foco na língua escrita. Portanto, de acordo com os autores supracitados, é consenso o fato de necessidade de considerar o aluno como sujeito capaz, não se limitando a ensinar apenas o mínimo e presumindo equivocadamente uma a incapacidade em aprender.

Contribuindo com a discussão, Anache e Resende (2016) pontuam, em seu estudo, as dificuldades vivenciadas por alunos com deficiência intelectual, destaca as condições de permanência e escolarização, posto que as metodologias adotadas pelo ensino regular nem sempre atendem às condições de aprendizagem desses alunos. As autoras indicam também que as avaliações se constituem em padrões normativos de condutas, constantemente ocorrendo comparações com os comportamentos ideais para faixa etária ou série escolar. Não obstante, também com base em pesquisa empírica aliada a uma revisão teórica quanto ao funcionamento cognitivo na deficiência intelectual, Schipper e Vestena (2016) enfatizam que a criança com deficiência intelectual em nível moderado apresenta singularidades do raciocínio, opera de forma pré-lógica com esquemas intuitivos, demonstra uma fragilidade do pensamento em 
consequência da invariância do raciocínio oscilante, levando a um falso equilíbrio por ausência de mobilidade interna. Dessa forma, as pesquisadoras consideram a possibilidade de o aluno suplantar os estágios elementares; para tanto, cabe ao professor potencializar os mecanismos de equilibração, a fim de que o desenvolvimento cognitivo seja estimulado pela ação do sujeito e não por submissão intelectual.

Ainda no tocante a aprendizagem de crianças com deficiência intelectual, o estudo de Bezerra (2017) salienta a importância da mediação verbal, por meio da oralidade, para o desenvolvimento linguístico-cognitivo dos alunos com deficiência intelectual, destacando as funções psicológicas superiores. Além disso, aponta que raramente se investe na comunicação com eles, em razão de delongarem mais a compreender as situações apresentadas, necessitarem de direcionamento sistemático do interlocutor para a generalização de conceitos e pela dificuldade da expressão verbal que possuem.

Já os estudos de Benitez e Domeniconi (2012) e Haquin, Cornejo e Molina (2016) encontramos a discussão para análise das verbalizações desses estudantes. No primeiro estudo, as autoras Benitez e Domeniconi categorizam e quantificam dicas verbais fornecidas pelos familiares de sujeitos com deficiência intelectual durante o acompanhamento das tarefas de casa que vislumbram a aprendizagem da leitura e escrita, como resultados constataram duas categorias: adequadas (proporcionar instrução na tarefa e fazer elogios) e inadequadas (apontar erros na resposta do sujeito e responder por ele). O estudo de Haquin, Cornejo e Molina (2016) trazem um recorte de uma pesquisa maior, em que analisam a narração como instância discursiva autogerida para além da linguagem. A investigação corresponde às narrações de quinze estudantes do Chile com deficiência intelectual e desenvolvimento incipiente da linguagem oral, mas com intenção narrativa. O estudo revelou que as crianças com deficiência intelectual criam significados usando expressões que incluem pantomima, gestos icônicos e, acima de tudo, gestos dêiticos, estáticos e dinâmicos, de modo a construir uma estrutura discursiva básica, realizando uma ordem temporal e dando significado ao contexto. A investigação é sediada em uma perspectiva multimodal que considera os recursos usados para construir significados, sem focar exclusivamente na linguagem oral.

Assim, em continuidade nessa exposição, temos 5 (cinco) artigos que tem como centro a tematização da inclusão escolar de alunos com deficiência intelectual, sendo que: (i) Pedraza Medina e Acle Tomasini (2009) analisam as formas de interação que ocorrem em salas de aula que incluem crianças com deficiência intelectual; (ii) Bezerra e Araújo (2011) apresentam uma reflexão filosófica sobre a inclusão escolar de alunos com deficiência intelectual por meio de um exercício crítico-dialético, objetivando detectar as contradições do fenômeno estudado; (iii) 
Toledo e Vitaliano (2012) investigam a eficácia de um programa de formação de professores numa Escola Estadual dos Anos Finais do Ensino Fundamental no Paraná, com vistas a favorecer o processo de inclusão de alunos com deficiência intelectual; (iv) Lopes e Marquezine (2012) apontam, a percepção dos professores sobre a importância da sala de recursos multifuncionais no processo de inclusão do aluno com deficiência intelectual no ensino regular; (v) Araújo e Almeida (2014) apresentam as possíveis contribuições do trabalho colaborativo entre professor de educação especial, ensino comum e outros profissionais como uma possibilidade para favorecer a inclusão nas escolas, não apenas no campo da intervenção, mas também no âmbito da prevenção, reflexão e transformação do meio escolar.

Em contrapartida, 3 (três) trabalhos direcionam o olhar para o processo de escolarização de sujeitos com deficiência intelectual: (i) Abdelhameed (2010) apresenta uma visão geral do desenvolvimento e prestação de serviços educacionais para crianças com deficiência intelectual no Egito; (ii) Santos (2012) traz em sua pesquisa de cunho bibliográfico, uma descrição sobre as características da deficiência intelectual no que se refere ao quadro principal do déficit cognitivo (funções intelectuais) e adaptativo (funções sociais, emocionais e práticas) e, posteriormente, delineia e analisa as possibilidades da prática pedagógica no contexto escolar; (iii) Maturana e Mendes (2017) investigam as concepções de alunos com deficiência intelectual sobre o processo de escolarização (escola especial comum).

Para concluir os apontamentos gerais do quantitativo de artigos publicados sobre a deficiência intelectual, destacamos que 3 (três) trabalhos estão relacionados ao tema das tecnologias: (i) Hein et al. (2010) verificam a eficácia da intervenção com o software alfabetização fônica computadorizada junto a estudantes com deficiência intelectual; (ii) Pedro e Chacon (2013) propõem atividades específicas de informática, por meio do uso de softwares educativos; (iii) Vives et al. (2017) elaboram um conjunto de jogos com acesso livre para crianças com deficiência cognitiva leve, cuidadores e pares, a fim de facilitar a inclusão.

Importante assinalar que outros 2 (dois) estudos desse levantamento que envidamos, abordam a questão da conceituação da deficiência intelectual como objeto de investigação: (i) Sanches-Ferreira, Lopes-dos-Santos e Santos (2012) explicitam as implicações da desconstrução do conceito de deficiência intelectual, advogam subsequente mudança para a designação de incapacidade ${ }^{2}$ intelectual; (ii) Videa (2016) apresenta dados, critérios e reflexões sobre a deficiência intelectual a partir de uma avaliação da situação atual na Bolívia.

\footnotetext{
${ }^{2}$ Para estes autores “a incapacidade é encarada, não como característica intrínseca da pessoa, mas como o resultado do desajustamento entre as funcionalidades do indivíduo e as solicitações dos cenários onde ele é chamado a participar" (p. 553).
} 
No que se refere ao segundo descritor "alfabetização e letramento" elaboramos o Quadro 2 que também delineia os autores, ano de publicação e título do artigo das produções, com o intuito de mostrarmos um panorama do inventário que realizamos.

Quadro 2: Levantamento de artigos publicados sobre alfabetização e letramento em periódicos nacionais e internacionais na base de dados SciELO.

\begin{tabular}{|c|c|}
\hline Autor(es)/Ano & Título \\
\hline 1. Soares $(2002)$ & Novas práticas de leitura e escrita: letramento na cibercultura \\
\hline 2. Lemke (2010) & Letramento metamidiático: transformando significados e mídias \\
\hline 3. Berberian et al. (2013) & $\begin{array}{l}\text { Análise do conhecimento de professores atuantes no ensino fundamental } \\
\text { acerca da linguagem escrita na perspectiva do letramento }\end{array}$ \\
\hline 4. Street (2013) & $\begin{array}{l}\text { Políticas e práticas de letramento na Inglaterra: uma perspectiva de } \\
\text { letramentos sociais como base para uma comparação com o Brasil }\end{array}$ \\
\hline $\begin{array}{l}\text { 5. Tasca; Guedes-Pinto } \\
(2013)\end{array}$ & $\begin{array}{l}\text { A divulgação do conceito de letramento e o contexto da escola de nove anos: } \\
\text { o que dizem as professoras alfabetizadoras? }\end{array}$ \\
\hline 6. Saito; Ribeiro (2013) & $\begin{array}{l}\text { (Multi)letramento(s)digital(is) e teoria do posicionamento: análise das } \\
\text { práticas discursivas de professoras que se relacionaram com as tecnologias } \\
\text { da informação e comunicação no ensino público }\end{array}$ \\
\hline $\begin{array}{l}\text { 7. Euzébio; Cerutti-Rizzatti } \\
\text { (2013) }\end{array}$ & $\begin{array}{l}\text { Usos sociais da escrita: um estudo sobre práticas e eventos de letramento na } \\
\text { vivência de professoras alfabetizadoras }\end{array}$ \\
\hline 8. Delgado et al. (2015) & Perspectivas de letramento em sujeitos com déficit intelectual \\
\hline 9. Molyneux; Aliani (2016) & $\begin{array}{l}\text { Texts, talk and technology: the literacy practices of bilingually-educated } \\
\text { students }\end{array}$ \\
\hline $\begin{array}{l}\text { 10. Macedo; Almeida; } \\
\text { Tibúrcio (2017) }\end{array}$ & $\begin{array}{l}\text { Práticas de alfabetização com crianças de seis anos no ensino fundamental: } \\
\text { diferentes estratégias, diferentes concepções }\end{array}$ \\
\hline $\begin{array}{l}\text { 11. Martins; Carvalho; } \\
\text { Dangió (2018) }\end{array}$ & O processo de alfabetização: da pré-história da escrita a escrita simbólica \\
\hline 12. Pelosi et al. (2018) & $\begin{array}{l}\text { Atividades lúdicas para o desenvolvimento da linguagem oral e escrita para } \\
\text { crianças e adolescentes com Síndrome de Down }\end{array}$ \\
\hline $\begin{array}{l}\text { 13. Pertuzatti; Dickmann } \\
\text { (2019) }\end{array}$ & $\begin{array}{l}\text { Alfabetização e letramento nas políticas públicas: convergências e } \\
\text { divergências com a Base Nacional Comum Curricular (BNCC) }\end{array}$ \\
\hline
\end{tabular}

Fonte: Elaboração das pesquisadoras.

Entre os 13 trabalhos elencados, assinalamos que 5 (cinco) abordam especificamente sobre o letramento e/ou alfabetização, são eles: (i) Berberian et al. (2013) analisam o conhecimento que um grupo de professores tem sobre as concepções de escrita e o conceito de letramento; (ii) Tasca e Guedes-Pinto (2013) trazem para a discussão, a apreciação narrativa de professoras alfabetizadoras frente às propostas de ensino da escrita no contexto da divulgação dos estudos do letramento; (iii) Euzébio e Cerutti-Rizzatti (2013) também discutem o fenômeno do letramento a partir do discurso de professores alfabetizadores, porém, adotam uma abordagem qualitativa de implicações etnográficas, visando responder: como se caracterizam os usos sociais da escrita? Que práticas e eventos de letramento são possíveis depreender na vida cotidiana e no trabalho desses professores?; (iv) Street (2013) aponta em seu artigo as limitações das políticas e estratégias fundadas em premissas etnocêntricas, a partir da teoria do 
letramento enraizada na comparação intercultural dos usos sociais da leitura e da escrita; (v) Pertuzatti e Dickmann (2019) apresentam uma análise de conteúdo e documental em relação às convergências e divergências das indicações e conceitos de letramento e alfabetização presentes nas leis que regem o Ensino Fundamental, inclusive o documento preliminar da BNCC.

Outros 4 (quatro) artigos versam acerca do letramento digital: (i) Soares (2002) elabora uma sistematização do conceito de letramento, confrontando tecnologias tipográficas e tecnologias digitais de leitura e de escrita, a partir de diferenças relativas ao espaço da escrita e aos mecanismos de produção, reprodução e difusão da escrita; (ii) Lemke (2010) analisa a semiótica multimidiática do letramento situada em diferentes perspectivas, enunciando que nenhuma tecnologia é uma ilha, pois está situada em redes mais amplas e relacionada a outras práticas culturais; (iii) Saito e Ribeiro (2013) investigam as práticas discursivas de três professoras que se relacionaram com as Tecnologias da Informação e Comunicação (TICs) no processo de ensino-aprendizagem de uma escola pública na cidade de Juiz de Fora (MG); (iv) Molyneux e Aliani (2016) trazem, em seu estudo, uma análise das práticas de letramento digital e linguagem utilizada por 68 estudantes de três escolas primárias na Austrália.

Na sequência de apreciação dos estudos mapeados, 2 (dois) tratam do processo de alfabetização: (i) Macedo, Almeida e Tibúrcio (2017) discutem sobre duas práticas de alfabetização adotadas pelas docentes para o ensino da leitura e da escrita a crianças de seis anos - uma primeira, cujo ponto de partida para a construção dos eventos de letramento é determinada pela letra do alfabeto e, uma segunda, com o predomínio do texto e contexto; (ii) Martins, Carvalho e Dangió (2018) apresentam elementos que contribuem para compreensão dos processos psíquicos mediados na aprendizagem da escrita, evidenciando o transcurso da pré-historia da escrita à escrita simbólica.

Ressaltamos que apenas 2 (dois) trabalhos interligam as temáticas de alfabetização e letramento com a deficiência intelectual: (i) Delgado et al. (2015) evidenciam em seu estudo uma discussão teórica quanto a perspectiva do letramento junto a sujeitos com deficiência intelectual; (ii) Pelosi et al. (2018) investigam os resultados produzidos por uma oficina de linguagem, evidenciando o estímulo das habilidades fonológicas, e a compreensão do sistema alfabético, num grupo de cinco crianças e adolescentes com Síndrome de Down.

Quanto ao terceiro descritor "aplicativo" ordenamos as produções por autores, ano de publicação e título do artigo, disponibilizando-as no quadro seguinte: 
Quadro 3: Levantamento de artigos publicados sobre aplicativos em periódicos nacionais e internacionais na base de dados SciELO.

\begin{tabular}{|ll|l|}
\hline \multicolumn{2}{|c|}{ Autor(es)/Ano } & \multicolumn{1}{c|}{ Título } \\
\hline 1. & $\begin{array}{l}\text { Jordan; Nohama; Britto- } \\
\text { Júnior (2009) }\end{array}$ & $\begin{array}{l}\text { Software Livre de produção textual com predição de palavras: um aliado do } \\
\text { aluno especial }\end{array}$ \\
\hline $\begin{array}{l}\text { 2. } \\
\text { Juttel; Kalempa; Pykosz }\end{array}$ & $\begin{array}{l}\text { Alfabetizando através da realidade aumentada: desenvolvimento de um } \\
\text { aplicativo de auxílio à alfabetização utilizando a realidade aumentada para } \\
\text { dispositivos móveis }\end{array}$ \\
\hline $\begin{array}{l}\text { 3. } \\
\text { Sánchez-Álvarez; } \\
\text { Zapata-Jaramillo; }\end{array}$ & $\begin{array}{l}\text { Heuristic assessment of software usability to facilitate computer use for } \\
\text { Jeople with motor disabilities }\end{array}$ \\
\hline 4. & Voltolini (2018) & $\begin{array}{l}\text { Programa Palma: dispositivos móveis e aplicativo como ferramenta para } \\
\text { alfabetização }\end{array}$ \\
\hline 5. & Barbosa; De Sá (2018) & $\begin{array}{l}\text { MapVoice: computational tool to aid in learning cartography for the } \\
\text { visually impaired }\end{array}$ \\
\hline
\end{tabular}

Fonte: Elaboração das pesquisadoras.

A partir do levantamento em relação a esse descritor, percebemos que do quantitativo total de 6 (seis) estudos, 2 (dois) discutem sobre a importância do aplicativo móvel para contribuir com a alfabetização dos sujeitos: (i) Juttel, Kalempa e Pykosz (2015) discutem uma forma de conciliar a alfabetização infantil à tecnologia, utilizando o desenvolvimento de um aplicativo capaz de auxiliar o processo de alfabetização através da realidade aumentada; (ii) Voltolini (2018) analisa os pressupostos do Programa Palma para dispositivos móveis que combinam sons, letras e imagens para apoiar e favorecer a alfabetização de sujeitos em fase inicial ou com dificuldades de aprendizagem.

Em particular, trazemos à baila, outro artigo, de Jordan, Nohama e Britto-Júnior (2009) que apresenta os resultados obtidos com a aplicação de um simulador de teclado em conjunto com uma técnica de predição de palavras baseada nos grupos das classes gramaticais da língua portuguesa, possibilitando ao usuário, a produção de textos com qualidade gramatical. Os resultados desse estudo apontam que o uso do aplicativo amplia a comunicação de adolescentes com sequelas advindas de paralisia cerebral e pode facilitar o processo de aprendizagem da linguagem escrita.

Outras particularidades que cabem destacar: 2 (dois) artigos, em especifico, (SánchezÁlvarez, Zapata-Jaramillo e Jiménez-Builes, 2017; Barbosa e De Sá, 2018) não versam sobre a temática de alfabetização ou linguagem escrita, nem sobre a deficiência intelectual. $\mathrm{O}$ primeiro refere-se a um método com enfoque heurístico para avaliar a usabilidade de software desenhado para facilitar o acesso à computação a pessoas com deficiência motriz. O segundo traz um recurso habilitado a estudantes cegos ou com deficiência visual, da educação básica, para aprendizagem de cartografia em aulas de Geografia que se consistiu no desenvolvimento do 
aplicativo MapVoice. Em vista disso, enfatizamos que, apesar do panorama diversificado de trabalhos, não foi encontrado nenhum estudo abordando o uso de aplicativos de leitura e escrita para alfabetização e letramento da criança com deficiência intelectual, objeto de investigação que a nossa pesquisa se propõe investigar.

Outra questão a ser evocada é o fato de que, apesar do panorama diversificado de trabalhos levantados por nós nesse mapeamento, não foi encontrado nenhum estudo abordando as potencialidades dos aplicativos de leitura e escrita para alfabetização e letramento de crianças com deficiência intelectual, objeto de nossa pesquisa de doutorado já citada, para a qual procedemos esse levantamento realizado à ocasião da construção do Estado da Questão e que aqui socializamos, posto que consideramos importante divulgar com vias de ampliação/atualização da área.

Em relação ao terceiro e último descritor “tecnologia móvel”, apresentamos o Quadro 4 que indica os autores, ano de publicação e título do artigo respectivamente.

Quadro 4: Levantamento de artigos publicados sobre tecnologia móvel em periódicos nacionais e internacionais na base de dados SciELO.

\begin{tabular}{|ll|l|}
\hline \multicolumn{2}{|c|}{ Autor(es)/Ano } & \multicolumn{1}{c|}{ Título } \\
\hline $\begin{array}{l}\text { 1. } \\
\text { Santarosa; Conforto }\end{array}$ & $\begin{array}{l}\text { Tecnologias Móveis na inclusão escolar e digital de estudantes com } \\
\text { Transtornos de Espectro Autista }\end{array}$ \\
\hline 2. & Reinaldo et al. (2016) & $\begin{array}{l}\text { Impasse aos desafios do uso de Smartphones em sala de aula: investigação } \\
\text { por grupos focais }\end{array}$ \\
\hline 3. & Martínez; Duart (2016) & $\begin{array}{l}\text { Nuevas tendencias de aprendizaje colaborativo en e-learning: claves para } \\
\text { su implementación efectiva }\end{array}$ \\
\hline 4. & $\begin{array}{l}\text { Chacón-Ortiz; } \\
\text { Camacho-Gutiérrez; } \\
\text { Heredia-Escorza (2017) }\end{array}$ & $\begin{array}{l}\text { Conocimientos sobre aprendizaje móvil e integración de dispositivos } \\
\text { móviles en docentes de la Universidad Nacional de Costa Rica }\end{array}$ \\
\hline 5. & $\begin{array}{l}\text { Sanromà-Giménez; } \\
\text { Lázaro-Cantabrana; } \\
\text { Gisbert-Cervera (2017) }\end{array}$ & $\begin{array}{l}\text { La tecnología móvil: } \text { una herramienta para la mejora de la inclusión digital } \\
\text { de las personas con TEA }\end{array}$ \\
\hline
\end{tabular}

Fonte: Elaboração das pesquisadoras.

Sobre esses trabalhos, apontamos que 3 (três) discutem sobre o uso de dispositivos móveis voltados para o processo de aprendizagem: (i) Reinaldo et al. (2016) evidenciam as vantagens e limitações da utilização dos smartphones como recurso ferramental durante o processo de ensino-aprendizagem do estudante em sala de aula; (ii) Martínez e Duart (2016) abordam as tendências que existem no novo cenário virtual de ensino e aprendizagem em relação à aprendizagem colaborativa; (iii) Chacón-Ortiz, Camacho-Gutiérrez e HerediaEscorza (2017) debatem acerca do uso de estratégias tecnológicas mediadas por dispositivos eletrônicos portáteis, celulares e tablets, e exploram, do ponto de vista educacional, as implicações que resultam da irrupção diária destas no contexto universitário. 
Por outro lado, 2 (dois) estudos apesar de também remeterem à utilização de dispositivos móveis, enfocam especificamente no auxílio a alunos com Autismo: Santarosa e Conforto (2015) debatem acerca dos limites e possibilidades da configuração tecnológica para o processo de inclusão escolar e digital de estudantes com Transtornos de Espectro Autista; e, Sanromà-Giménez, Lázaro-Cantabrana e Gisbert-Cervera (2017) apresentam uma aproximação teórica do contexto social e educacional em relação às dimensões da inclusão digital de pessoas com Autismo e o uso de tecnologias digitais no processo de aprendizagem. Logo, constatamos nesse levantamento procedido, a presença de apenas iniciativas de pesquisas que interligam tecnologias em geral ou tecnologias móveis junto a estudantes com TEA.

\section{Levantamento de estudos científicos em periódicos específicos}

Neste tópico, trazemos o levantamento de estudos científicos publicados em periódicos específicos nacionais da área de educação especial, visto que reúne o maior número de produções relacionadas ao nosso campo de pesquisa. Além de, no próprio levantamento, termos constatado na base de dados SciELO apenas algumas publicações de periódicos específicos. Portanto, optamos por consultar todos os números de publicações da Revista Brasileira de Educação Especial (RBEE, Qualis A1) e Revista Educação Especial (REE, Qualis A2) no interstício de 2015-2019, que se refere ao último quadriênio.

\begin{tabular}{ccc} 
Quadriênio & $\begin{array}{c}\text { Quantitativo de } \\
\text { publicações }\end{array}$ & $\begin{array}{c}\text { Quantitativo de publicações } \\
\text { relacionadas ao tema }\end{array}$ \\
\hline $2015-2019$ & 571 & 14 \\
\hline
\end{tabular}

Fonte: Dados coletados entre agosto de 2018 e julho de 2019, todavia atualizados em março de 2020.

Dessa forma, de um total de 571 (100\%) artigos consultados, foi possível identificar que somente $14(2,4 \%)$ trabalhos abordam temáticas (inclusão, aprendizagem, práticas dos professores, leitura e escrita) relacionadas à deficiência intelectual, conforme detalhamos a seguir:

Quadro 5: Levantamento de artigos publicados relacionados a deficiência intelectual na Revista Brasileira de Educação Especial e Revista Educação Especial.

\begin{tabular}{|c|c|c|}
\hline \multicolumn{2}{|c|}{ Autor(es)/Ano } & $\begin{array}{l}\text { Título } \\
\end{array}$ \\
\hline $\begin{array}{l}\text { 1. Caramori; } \\
(2015)\end{array}$ & Dall'acqua & $\begin{array}{l}\text { Estratégias pedagógicas empregadas por professores de educação } \\
\text { especial aos seus alunos com deficiência intelectual severa: um estudo } \\
\text { descritivo da prática docente }\end{array}$ \\
\hline
\end{tabular}




\begin{tabular}{|ll|l|}
\hline 2. & Cunha; Rossato (2015) & $\begin{array}{l}\text { A singularidade dos estudantes com deficiência intelectual frente ao } \\
\text { modelo homogeneizado da escola: reflexões sobre o processo de } \\
\text { inclusão }\end{array}$ \\
\hline 3. $\quad$ Fantacini; Dias (2015) & $\begin{array}{l}\text { Professores do atendimento educacional especializado e a organização } \\
\text { do ensino para o aluno com deficiência intelectual }\end{array}$ \\
\hline 4. Santos; Martins (2015) & $\begin{array}{l}\text { Práticas de professores frente ao aluno com deficiência intelectual em } \\
\text { classe regular }\end{array}$ \\
\hline 5. Barby; Guimarães (2016) & $\begin{array}{l}\text { Desenvolvimento de habilidades metafonológicas e aprendizagem da } \\
\text { leitura e da escrita em alunos com síndrome de down }\end{array}$ \\
\hline 6. Campos; Glat (2016) & $\begin{array}{l}\text { Procedimentos favoráveis ao desenvolvimento de uma criança com } \\
\text { síndrome de down numa classe comum }\end{array}$ \\
\hline 7. Oleques (2016) & $\begin{array}{l}\text { Desenho e escrita: características na produção gráfica de duas crianças } \\
\text { com síndrome de down }\end{array}$ \\
\hline 8. Azevedo; Damke (2017) & $\begin{array}{l}\text { A criança com síndrome de down: o sentido da inclusão no contexto da } \\
\text { exclusão }\end{array}$ \\
\hline 9. Barby; Guimarães; Vestena & $\begin{array}{l}\text { A construção da escrita em crianças com síndrome de down incluídas } \\
\text { em escolas regulares }\end{array}$ \\
\hline 10. Padilha (2017) & $\begin{array}{l}\text { Desenvolvimento psíquico e elaboração conceitual por alunos com } \\
\text { deficiência intelectual na educação escolar }\end{array}$ \\
\hline 11. Viana; Gomes (2017) & $\begin{array}{l}\text { A produção escrita de pessoas com deficiência intelectual na interação } \\
\text { com as tecnologias digitais da informação e comunicação }\end{array}$ \\
\hline 12. Shimazaki et al. (2018) & $\begin{array}{l}\text { O trabalho com o gênero textual história em quadrinhos com alunos que } \\
\text { possuem deficiência intelectual }\end{array}$ \\
\hline 13. Delgado et al. (2019) & $\begin{array}{l}\text { Estratégias de letramento voltadas à intervenção fonoaudiológica em } \\
\text { pessoas com síndrome de down }\end{array}$ \\
\hline 14. Freitas; Ribeiro (2019) & $\begin{array}{l}\text { Neuroplasticidade na educação e reabilitação cognitiva da deficiência } \\
\text { intelectual }\end{array}$ \\
\hline
\end{tabular}

Fonte: Elaboração das pesquisadoras.

Desse modo, após uma leitura minuciosa dos estudos elencados, assinalamos que 4 (quatro) versam sobre as práticas dos professores: (i) Caramori e Dall'acqua (2015) desenvolvem um estudo descritivo da prática docente a partir das estratégias pedagógicas utilizadas por professores da educação especial aos seus alunos com deficiência intelectual severa; (ii) Fantacini e Dias (2015) investigam a respeito da organização do ensino para o aluno com deficiência intelectual no âmbito do Atendimento Educacional Especializado, enfocando o ambiente da sala de aula comum e da sala de recursos multifuncionais; (iii) Santos e Martins (2015) analisam as práticas pedagógicas dos professores frente a alunos com deficiência intelectual matriculados na escola comum; (iv) Campos e Glat (2016) apresentam um recorte de uma pesquisa maior que investigou a concepção de ensinoaprendizagem e as práticas pedagógicas de uma professora na relação com uma criança com Síndrome de Down. Esses estudos evidenciam por unanimidade a necessidade da busca de novos conhecimentos, saberes e formação dos professores para colaborar efetivamente no processo de ensino e aprendizagem desses estudantes. 
Ainda quanto à apreciação dos artigos, 5 (cinco) tratam da aprendizagem na leitura e escrita por sujeitos com deficiência intelectual: Barby e Guimarães (2016) analisam os resultados produzidos pela aplicação de um programa de intervenção pedagógica que englobou o ensino do alfabeto associado ao treinamento de habilidades metafonológicas com vistas à aprendizagem da leitura e escrita; Oleques (2016) destaca aspectos do desenvolvimento do desenho e da escrita de crianças com Síndrome de Down. Em proximidade com o trabalho anterior, Barby, Guimarães e Vestena (2017) pesquisam sobre o desempenho na produção escrita; Viana e Gomes (2017) também abordam a produção escrita de sujeitos com deficiência intelectual, porém, investigando se a interação com as tecnologias digitais da informação e comunicação influencia o desenvolvimento das competências de escrita.

Já Delgado et al. (2019) discutem sobre a caracterização das estratégias de letramento usadas em intervenções fonoaudiológica junto a pessoas com Síndrome de Down. Dentre elas, com enfoque na modalidade oral da língua, citamos: a leitura de livros infantis, atividades de psicomotricidade relacionando à linguagem oral, leitura de histórias e recontagem, utilização e exploração de músicas infantis o uso de jogos e ações digitais por meio da criação de páginas na $w e b$, entre outras estratégias. Esses estudos, em linhas gerais, constatam as implicações da mediação para aprendizagem da leitura e da escrita, seja na relação da linguagem oral, aprimoramento da atenção, memória, motivação ou estratégias didáticas de trabalho pedagógico com diversidade de gêneros textuais e do letramento digital e do uso de tecnologias.

Dando continuidade à análise dos demais estudos, 2 (dois) se dedicam a discutir a inclusão escolar do aluno com deficiência intelectual, a partir de seus recortes específicos: (i) Cunha e Rossato (2015) analisam a singularidade de alunos com deficiência intelectual frente ao modelo homogeneizado da escola de conceber os processos de aprendizagem, tecendo críticas e apontando perspectivas teóricas e abordagens que as fundamentam; (ii) Azevedo e Damke (2017) tecem reflexões acerca do sentido da inclusão no contexto da exclusão, a partir de uma investigação que acompanha o desenvolvimento de uma aluna com Síndrome de Down.

Outros 3 (três) artigos de Padilha (2017), Shimazaki et al. (2018) e Freitas e Ribeiro (2019) enfocam na aprendizagem de alunos com deficiência intelectual. O primeiro dá destaque à elaboração conceitual, própria da educação escolar, pelos alunos com deficiência intelectual, evidenciando que práticas pedagógicas organizadas e sistematizadas, com estratégias desenvolvidas por meio do material adequado constituem nas possibilidades de aprendizagem desses alunos, caminhando do conhecimento espontâneo, confuso, genérico para o saber consciente e científico. O segundo aborda estratégias desenvolvidas para que indivíduos com deficiência intelectual se apropriem dos conceitos científicos presentes nas histórias em 
quadrinhos. O terceiro descreve o perfil funcional da deficiência intelectual, apresentando técnicas para a adaptação curricular de sujeitos com deficiência intelectual, tendo como foco o elo entre a educação e a neuroplasticidade.

Tais estudos enfocam no sujeito como o centro de todo o processo de aprendizagem a fim de possibilitar uma aprendizagem mais efetiva. Sobretudo, isso implica em práticas reflexivas comprometidas com o processo de ensino aprendizagem desses estudantes através de uma estimulação adequada, em contextos mediados, em que os sujeitos com deficiência intelectual apresentem capacidade de construir e de estimular os instrumentos cognitivos imprescindíveis para aquisição dos esquemas das operações concretas. Por conseguinte, o êxito do processo de aprendizagem dos mesmos depende de um conjunto de fatores que, se forem proporcionados, contribuirão de maneira significativa para o sucesso em seu desenvolvimento.

\section{Mapeamento de trabalhos publicados nas Reuniões Anuais da ANPEd- GT Educação Especial}

As produções ora registradas são provenientes do mapeamento realizado em renomado evento científico da área da Educação, a Reunião Anual da ANPEd. Dessa maneira, consultamos todas as publicações disponíveis no site, selecionamos a modalidade "Trabalho e Pôster", no eixo temático destinado a Educação Especial- GT 15 e obtemos os seguintes resultados:

\begin{tabular}{|c|c|c|}
\hline N/Descrição & Quantitativo de publicações & $\begin{array}{l}\text { Quantitativo de publicações } \\
\text { relacionadas ao tema }\end{array}$ \\
\hline $38^{\mathrm{a}}$ Reunião Nacional & 20 & - \\
\hline $37^{a}$ Reunião Nacional & 29 & 02 \\
\hline $36^{\mathrm{a}}$ Reunião Nacional & 20 & 01 \\
\hline $35^{\mathrm{a}}$ Reunião Anual & 19 & 04 \\
\hline $34^{\mathrm{a}}$ Reunião Anual & 24 & 01 \\
\hline $33^{\mathrm{a}}$ Reunião Anual & 10 & - \\
\hline $32^{\mathrm{a}}$ Reunião Anual & 15 & - \\
\hline $31^{\mathrm{a}}$ Reunião Anual & 15 & - \\
\hline $30^{\mathrm{a}}$ Reunião Anual & 15 & 01 \\
\hline $29^{a}$ Reunião Anual & 11 & 02 \\
\hline $28^{\mathrm{a}}$ Reunião Anual & 23 & 01 \\
\hline $27^{\mathrm{a}}$ Reunião Anual & 13 & 01 \\
\hline $26^{\mathrm{a}}$ Reunião Anual & 19 & 01 \\
\hline $25^{\mathrm{a}}$ Reunião Anual & 08 & 01 \\
\hline $24^{\mathrm{a}}$ Reunião Anual & 19 & 03 \\
\hline $23^{\mathrm{a}}$ Reunião Anual & 16 & 02 \\
\hline Total & 276 & 20 \\
\hline
\end{tabular}

Fonte: Dados coletados entre agosto de 2018 e novembro de 2019, todavia atualizados em fevereiro de 2020. 
Com o propósito de compilar e sintetizar os achados, destacamos o Quadro 6, que específica os respectivos autores, ano e título dos estudos relacionados as temáticas de deficiência intelectual, alfabetização, letramento e tecnologia.

Quadro 6: Levantamento de trabalhos publicados relacionados a deficiência intelectual, alfabetização/letramento e tecnologia no GT 15-Educação Especial das reuniões da Anped.

\begin{tabular}{|c|c|}
\hline Autor(es)/Ano & Título \\
\hline 1. Padilha (2000) & $\begin{array}{l}\text { A constituição do sujeito simbólico: para além dos limites impostos à } \\
\text { deficiência mental }\end{array}$ \\
\hline 2. Silva (2000) & Processos de ensino na educação dos deficientes mentais \\
\hline 3. Camargo (2001) & $\begin{array}{l}\text { Sentidos construídos sobre a independência de jovens com síndrome de } \\
\text { down por um grupo de pais e profissionais. }\end{array}$ \\
\hline 4. Victor (2001) & $\begin{array}{l}\text { Aspectos presentes na brincadeira de faz-de-conta da criança com } \\
\text { síndrome de down }\end{array}$ \\
\hline 5. Neves; Mendes (2001) & $\begin{array}{l}\text { Movimentos sociais e a auto-advocacia: analisando a participação de } \\
\text { pessoas com deficiência mental }\end{array}$ \\
\hline 6. Souza (2002) & $\begin{array}{l}\text { O impacto da psicologia na construção histórica do conceito de deficiência } \\
\text { mental }\end{array}$ \\
\hline $\begin{array}{l}\text { 7. Gomes; } \\
(2003)\end{array}$ & $\begin{array}{l}\text { A emergência das estratégias de leitura em sujeitos com deficiência } \\
\text { mental }\end{array}$ \\
\hline 8. Maffezol; Góes (2004) & $\begin{array}{l}\text { Jovens e adultos com deficiência mental: seus dizeres sobre o cenário } \\
\text { cotidiano de suas relações pessoais e atividades }\end{array}$ \\
\hline 9. Galvão Filho (2005) & $\begin{array}{l}\text { O desenvolvimento de projetos pedagógicos em ambiente computacional } \\
\text { e telemático com alunos com paralisia cerebral }\end{array}$ \\
\hline 10. Ferri (2006) & $\begin{array}{l}\text { Currículo e diferença: processos de seleção e organização de } \\
\text { conhecimentos para atendimento educacional de alunos com histórico de } \\
\text { deficiência mental }\end{array}$ \\
\hline 11. Carneiro (2006) & O uso de métodos narrativos na pesquisa sobre a deficiência mental \\
\hline 12. Miranda e Rosa (2007) & $\begin{array}{l}\text { As múltiplas dimensões educativas da escola para o aluno com deficiência } \\
\text { mental }\end{array}$ \\
\hline 13. Pletsch; Glat (2011) & $\begin{array}{l}\text { A escolarização de alunos com deficiência intelectual em diferentes } \\
\text { contextos educacionais }\end{array}$ \\
\hline 14. Gomes (2012) & $\begin{array}{l}\text { A coerência textual de alunos com síndrome de down: uma análise da } \\
\text { produção escrita através do uso de imagens }\end{array}$ \\
\hline 15. Bridi (2012) & $\begin{array}{l}\text { A produção diagnóstica de alunos com deficiência mental no contexto do } \\
\text { atendimento educacional especializado }\end{array}$ \\
\hline 16. Camargo (2012) & $\begin{array}{l}\text { O benefício de prestação continuada e a inserção do indivíduo com } \\
\text { deficiência intelectual no mundo do trabalho }\end{array}$ \\
\hline $\begin{array}{l}\text { 17. Silva; Oliveira; Ferreira } \\
\text { (2012) }\end{array}$ & $\begin{array}{l}\text { Significados e sentidos na construção da identidade do deficiente } \\
\text { intelectual para além de eufemismos }\end{array}$ \\
\hline 18. Bridi (2013) & Deficiência mental: possíveis leituras a partir dos manuais diagnósticos \\
\hline 19. Carneiro (2015) & $\begin{array}{l}\text { A deficiência intelectual como produção social: reflexões a partir da } \\
\text { abordagem histórico-cultural }\end{array}$ \\
\hline 20. Pinto; Camargo (2015) & $\begin{array}{l}\text { A inter-relação entre a produção de sentidos e o aprendizado da escrita de } \\
\text { uma criança com atrasos neste processo: um olhar a partir da perspectiva } \\
\text { bakhtiniana }\end{array}$ \\
\hline
\end{tabular}

Fonte: Elaboração das pesquisadoras. 
Logo, destacamos que dos 20 trabalhos listados, 5 (cinco) debatem sobre o cenário sociocultural da deficiência intelectual: Neves e Mendes (2001) desenvolvem uma discussão em torno dos movimentos sociais para construção da cidadania das pessoas com deficiências no âmbito da sociedade brasileira, comparando com um movimento emergente do empoderamento da pessoa com deficiência intelectual; Souza (2002) apresenta o impacto da psicologia na construção do conceito de deficiência intelectual; Maffezol e Góes (2004) analisam nos discursos de sujeitos com deficiência intelectual, os modos que reconhecem e significam sua inserção nos espaços do cotidiano; Carneiro (2006) discute a deficiência intelectual como uma condição estabelecida a partir das relações sociais travadas com sujeitos que possuem características significativamente diferentes da maioria da população e não conforme uma incapacidade própria do sujeito; e, em um estudo posterior, Carneiro (2015) traz reflexões acerca da referida deficiência apoiada na teoria histórico-cultural. Importante reconhecer que esses trabalhos incorporam os avanços estabelecidos quanto à compreensão da deficiência intelectual no modelo social, conforme plasmada na Convenção Internacional sobre os Direitos das Pessoas com Deficiência (2009).

Na sequência de apontamentos, 4 (quatro) estudos têm uma abordagem centrada na pessoa com deficiência intelectual: Padilha (2000) evidencia as alterações significativas nos processos cognitivos mediados por processos simbólicos para além dos limites impostos ao sujeito com deficiência intelectual; Camargo (2001) investiga a construção dos sentidos sobre a independência de indivíduos com Síndrome de Down; Victor (2001) analisa como a criança com Síndrome de Down reconstrói a realidade objetiva dos objetos e das relações sociais em brincadeira de faz-de-conta; e, Silva, Oliveira e Ferreira (2012) abordam os significados e sentidos na construção da identidade da pessoa com deficiência intelectual, considerando as construções e terminologias que carregam materialidade de discursos e práticas que se traduzem na ordem das representações. Sobre tais pesquisas elencadas, sobressai a argumentação dos autores com base na teoria e referencial de Vygotsky, Bakhtin, Marx, Mouffe e/ou Laclau.

Outros 4 (quatro) trabalhos tratam da escolarização de alunos com deficiência intelectual: Silva (2000) discute o processo de ensino e a estruturação das práticas educativas oferecidas ao aluno com deficiência intelectual; Ferri (2006) dialoga sobre a organização dos conhecimentos selecionados para os estudantes com deficiência intelectual nas escolas regulares e especiais; Miranda e Rosa (2007) trazem uma análise do lugar que a escola representa na vida de adolescentes com deficiência intelectual, destacando suas experiências relacionadas à aquisição do conhecimento, socialização e autonomia; e, Pletsch e Glat (2011) 
desenvolvem um estudo acerca do processo de ensino-aprendizagem e a escolarização dos alunos em diversos contextos educacionais.

Ainda sobre as apreciações dos trabalhos mencionamos que 3 (três) enfocam o aprendizado da escrita: Gomes e Figueiredo (2003) analisam a emergência das estratégias de leitura em sujeitos com deficiência intelectual no decurso da aquisição da linguagem escrita; Gomes (2012) retrata a influência da mediação quanto à escrita de alunos com Síndrome de Down, averiguando se ocorre ou não diferenças qualitativas nas produções textuais, quando estes têm a oportunidade de produzir textos em situações de colaboração; e, Pinto e Camargo (2015) investigam a apropriação da escrita de um aluno com dificuldade de aprendizagem, ressaltando o papel da interlocução com este aluno para o desenvolvimento da sua produção escrita. Um traço comum a esses estudos é a reverberação de que estudantes com deficiência intelectual avançam nas elaborações conceituais quanto a aprendizagem da leitura e da escrita, posto que só têm um ritmo de aprendizagem diferente, com peculiaridades e características próprias, mas isso não as impossibilita de aprender.

Em contrapartida, 3 (três) estudos retratam o diagnóstico consoante a diferentes vieses: Bridi (2012) pontua acerca dos processos de identificação e diagnóstico dos alunos com deficiência intelectual no contexto do Atendimento Educacional Especializado; Camargo (2012) aborda os possíveis impactos do Benefício de Prestação Continuada na educação profissional para sujeitos com diagnóstico de deficiência intelectual; em investigação subsequente, Bridi (2013) investiga o que dizem os manuais diagnósticos acerca da deficiência intelectual, principalmente, em relação ao conceito da deficiência, critérios de diagnóstico e classificação.

Por fim, destacamos que identificamos apenas 1 (um) artigo nesse acervo que versa acerca da tecnologia: (i) Galvão Filho (2005) apresenta em seu estudo os avanços alcançados por alunos com Paralisia Cerebral, sem comprometimento intelectual, em seus processos de desenvolvimento e aprendizagem, quando envolvidos em projetos de ambiente/contexto computacional e telemático. Quando recortamos, em específico, a temática da alfabetização e letramento para crianças com deficiência intelectual por meio de tecnologias ou mídias computacionais e/ou aplicativos e dispositivos móveis, por exemplo, temos o seguinte panorama nos estudos consultados: somente figuram três estudos (HEIN et al., 2010; BENITEZ; DOMENICONI, 2012; VIANA; GOMES, 2017).

Por ser referida a nosso interesse de investigação de doutorado, tecemos algumas breves considerações que julgamos importantes, em relação a essa produções: no primeiro estudo ( HEIN et al), os autores evidenciam que desenvolveram um estudo com o "Software 
Alfabetização Fônica Computadorizada" para identificar os possíveis benefícios que estudantes com deficiência intelectual poderiam adquirir na aquisição de leitura, em razão dos relatos dos professores sobre as dificuldades que sentem em conduzir o processo de alfabetização e letramento desses sujeitos. Os resultados comunicados por meio dessa pesquisa evidenciaram progresso nas habilidades de escrita e leitura e nos indicadores de consciência fonológica, representando ganhos significativos na decodificação grafo-fonêmica. Constataram ainda que houve progresso na aprendizagem dos sujeitos, compatível a três anos de escolarização.

Já o segundo estudo apesar de os investigadores terem analisado a verbalização de familiares no decorrer da aprendizagem da leitura e escrita de sujeitos com deficiência intelectual operaram com um programa informatizado, denominado "Aprendendo a Ler e a Escrever em Pequenos Passos" de sigla ProgLeit, composto por quatro módulos ${ }^{3}$. Cumpri asseverar que as autoras do artigo não apresentam apreciação sobre os aspectos cognitivos desenvolvidos pelos sujeitos a partir do uso do programa, apenas pontuam que eles foram capazes de concluir o módulo com êxito.

Na sequência, a terceira produção também se utilizou das Tecnologias Digitais de Informação e Comunicação, mas com o objetivo de investigar se a mediação em contexto digital representava interferência acerca da qualidade das produções textuais, em face de aspectos semânticos e ortográficos da escrita de sujeitos com deficiência intelectual. O conceito de mediação trabalhado pelas autoras se fundamentou em Feuerstein (1997) e Vygotsky (1989). Os resultados demonstraram que os participantes da pesquisa dispuseram de competências para o uso de recursos disponíveis em meio digital, além de apresentarem uma evolução da escrita na ocasião em que as ações desses sujeitos foram mediadas.

O levantamento em relação a essa temática, em particular, vem retratar a importância de se averiguar mais profundamente como estes recursos digitais podem contribuir para aprendizagem da leitura e da escrita, visto que julgamos válido o enfoque sobre o uso de aplicativos educacionais em razão de vivermos numa sociedade imersa no mundo digital com diversos signos (imagético, sonoro, movimento), cada vez mais integrados a sociedade, junto a construção do conhecimento e as práticas sociais e interacionais de dimensão linguísticas, discursivas e textuais.

Assim, com base no inventariado desenvolvido foi possível explicitar o que existe na ciência atual sobre o vasto campo da deficiência intelectual, tecnologia móvel, aplicativo,

\footnotetext{
${ }^{3}$ Durante a pesquisa só foi aplicado o primeiro módulo (leitura de 51 palavras) através de um procedimento adaptado a necessidades específicas dos indivíduos, tendo mães e/ou responsáveis como monitores.
} 
alfabetização e letramento que certamente colaboram para a nossa pesquisa. Ainda que não identificamos nenhum estudo referindo-se a alfabetização e letramento de crianças com deficiência intelectual mediante o uso de aplicativos de leitura e escrita, mas sim, temáticas que se interligam nas seguintes combinações, como: "deficiência intelectual/ alfabetização e letramento", "deficiência intelectual/ alfabetização e letramento/tecnologia", "deficiência intelectual/tecnologia", "alfabetização e letramento/aplicativo", "alfabetização e letramento/tecnologia".

\section{Constatações e contribuições do inventário mapeado para a investigação}

O mergulho na literatura mapeada propiciou a oportunidade de referenciar uma relevante e extensiva quantidade de produções publicadas articuladas ao tema ora investigado "o uso de aplicativos de leitura e escrita na alfabetização e letramento de crianças com deficiência intelectual"; do total de 1644 (100\%) estudos consultados, 78 (4,7\%) apresentaram indícios de proximidade com o nosso objeto de pesquisa, abordando as temáticas de deficiência intelectual, alfabetização e letramento, tecnologia e/ou aplicativos. Porém, nenhum relacionando "deficiência intelectual/alfabetização e letramento/aplicativo" e "defíciência intelectual/aplicativo".

Neste ínterim, mencionamos que essas investigações científicas mapeadas e discutidas revelam o interesse dos pesquisadores por diversos enfoques. Dentre eles, evidenciamos: a aprendizagem e desenvolvimento de alunos com deficiência intelectual, a inclusão e escolarização, concepções de professores e suas percepções sobre o papel da mediação na aprendizagem, uso das tecnologias para o desenvolvimento de competências de escrita, intervenção com softwares e aplicativos móveis. Também notamos que, em geral, são poucos os trabalhos que interligam as tecnologias às deficiências e/ou transtornos, mais raros ainda aqueles que operam com dispositivos móveis e aplicativos.

Desse modo, compreendemos ainda que a busca por desvelar o tema em questão fez emergir, para nós, um campo profícuo para os mais diversos trabalhos/artigos, enveredandonos por áreas transversais e interdisciplinares como a linguística, tecnologia, psicologia, educação, comunicação, educação especial, inclusiva, ciências e saúde. Nesse processo, sublinhamos a pluralidade de olhares dirigidos acerca de questões ou elementos aparentemente idênticos, mas analisados a partir de referenciais convergentes e/ou divergentes como Vygotsky, Piaget, Feuerstein e Bakhtin. 
Por fim, considerando o que foi apresentado, cabe mencionar mais uma vez que a elaboração deste inventariado nos proporcionou mais conhecimento sobre o estado atual do nosso objeto de investigação, no caso "o uso de aplicativos de leitura e escrita na alfabetização e letramento de crianças com deficiência intelectual”, de modo a evitar vieses na conceituação de categorias teórico-empíricas e definição dos referenciais. Sobressai também a importância da construção/elaboração do Estado da Questão para trabalhos acadêmicos e para a pesquisa científica. Portanto, concluímos que esse exercício é primordial para conhecer "o que foi" e "o que está sendo" produzido por pesquisadores de diversas áreas, além de possibilitar confronto de elaboração própria com os estudos de outros investigadores.

\section{REFERÊNCIAS}

ABDELHAMEED, Hala. The development and provision of educational services for children with intellectual disabilities in Egypt. Revista Brasileira de Educação Especial,

Marília, v.16, n.1, p.3-18, 2010. Disponível em:

<http://www.scielo.br/pdf/rbee/v16n1/02.pdf>. Acesso em: 14 jan. 2020.

ANACHE, Alexandra Ayach; RESENDE, Dannielly Araújo Rosado. Caracterização da avaliação da aprendizagem nas salas de recursos multifuncionais para alunos com deficiência intelectual. Revista Brasileira de Educação, Rio de Janeiro, v.21, n.66, p. 569-591, 2016. Disponível: 〈http://www.scielo.br/pdf/rbedu/v21n66/1413-2478-rbedu-21-66-0569.pdf>. Acesso em: 03 ago. 2019.

ARAÚJO, Sandra Lúcia Silva; ALMEIDA, Maria Amélia. Contribuições da consultoria colaborativa para a inclusão de pessoas com deficiência intelectual. Revista Educação Especial, Santa Maria, v.27, n.49, p.341-352, 2014. Disponível em: <http://periodicos.ufsm.br/educacaoespecial/article/view/8639/pdf>. Acesso em: 06 ago. 2019.

AZEVEDO, Ana Paula da Silva; DAMKE, Anderléia Sotoriva. A Criança com síndrome de down: o sentido da inclusão no contexto da exclusão. Revista Educação Especial, Santa Maria, v.30, n.57, p.103-114, 2017. Disponível em:

<https://periodicos.ufsm.br/educacaoespecial/article/view/17862>. Acesso em: 07 abr. 2019.

BARBOSA, Leonardo Carlos; DE SÁ, Lucilene Antunes Correia Marques. MapVoice: computational tool to aid in learning cartography for the visually impaired. Boletim de Ciências Geodésicas, v.24, n.1, p.58-68, 2018. Disponível em:

<https://revistas.ufpr.br/bcg/article/view/58634/35041>. Acesso em: 07 abr. 2019.

BARBY, Ana Aparecida de Oliveira Machado; GUIMARÃES, Sandra Regina Kirchner. Desenvolvimento de habilidades metafonológicas e aprendizagem da leitura e da escrita em alunos com síndrome de down. Revista Brasileira de Educação Especial, Marília, v.22, n.3, p.381-398, 2016. Disponível em: <http://www.scielo.br/pdf/rbee/v22n3/1413-6538rbee-22-03-0381.pdf >. Acesso em: 11 set. 2019. 
BARBY, Ana Aparecida de Oliveira Machado; GUIMARÃES, Sandra Regina Kirchner; VESTENA, Carla Luciane Blum. A construção da escrita em crianças com síndrome de down incluídas em escolas regulares. Revista Educação Especial, Santa Maria, v.30, n.57, p.219234, 2017. Disponível em: 〈https://periodicos.ufsm.br/educacaoespecial/article/view/19944〉. Acesso em: 07 abr. 2019.

BENITEZ, Priscila; DOMENICONI, Camila. Verbalizações de familiares durante aprendizagem de leitura e escrita por deficientes intelectuais. Estudos de Psicologia, Campinas, v. 29, n. 4, p. 553-562, 2012. Disponível em: <http://www.scielo.br/pdf/estpsi/v29n4/v29n4a10.pdf>. Acesso em: 17 ago. 2018.

BERBERIAN, Ana Paula; BORTOLOZZI, Kyrlian Bartira; MASSI, Giselle; BISCOUTO, Ângela Regina; ENJIU, Andréa Jully; OLIVEIRA, Karina de Fátima Portela de. Análise do conhecimento de professores atuantes no ensino fundamental acerca da linguagem escrita na perspectiva do letramento. Revista CEFAC, São Paulo, v.15, n.6, p.1635-1642, 2013. Disponível em: <http://www.scielo.br/pdf/rcefac/v15n6/219-11.pdf>. Acesso em: 23 dez. 2018.

BEZERRA, Giovani Ferreira; ARAUJO, Doracina Aparecida de Castro. De volta à teoria da curvatura da vara: a deficiência intelectual na escola inclusiva. Educação em Revista, Belo Horizonte, v.27, n.2, p. 277-302, 2011. Disponível em:

<http://www.scielo.br/pdf/edur/v27n2/a13v27n2.pdf>. Acesso em: 07 jan. 2020.

BEZERRA, Giovani Ferreira. Mediação verbal para alunos com deficiência intelectual na sala de recursos multifuncionais: reflexões e (pro)posições. Práxis Educativa, Ponta Grossa, v.12, n.3, p.960-979, 2017. Disponível em:

<https://www.revistas2.uepg.br/index.php/praxiseducativa/article/view/10081/6002>. Acesso em: 05 jan. 2020.

BRIDI, Fabiane Romano de Souza. A produção diagnóstica de alunos com deficiência mental no contexto do atendimento educacional especializado. In: REUNIÃO ANUAL DA ANPED, 35, Porto de Galinhas, 2012. Anais eletrônicos... Porto de Galinhas: ANPEd, 2012.

Disponível em:

<http://35reuniao.anped.org.br/images/stories/trabalhos/GT15\%20Trabalhos/GT152070_int.pdf>. Acesso em: 20 out. 2019.

BRIDI, Fabiane Romano de Souza. Deficiência mental: possíveis leituras a partir dos manuais diagnósticos. In: REUNIÃO ANUAL DA ANPED, 36, Goiânia, 2013. Anais eletrônicos... Goiânia: ANPEd, 2013. Disponível em:

<http://www.anped.org.br/sites/default/files/gt15_3213_texto.pdf〉. Acesso em: 20 out. 2019.

CAMARGO. Evani Andreatta Amaral. Sentidos construídos sobre a independência de jovens com síndrome de down por um grupo de pais e profissionais. In: REUNIÃO ANUAL DA ANPED, 24, Caxambú, 2001. Anais eletrônicos... Caxambu: ANPEd, 2001. Disponível em: < http://24reuniao.anped.org.br/T1591013990038.doc>. Acesso em: 05 ago. 2019.

CAMARGO, Flávia Pedrosa de. O benefício de prestação continuada e a inserção do indivíduo com deficiência intelectual no mundo do trabalho. In: REUNIÃO ANUAL DA ANPED, 35, Porto de Galinhas, 2012. Anais eletrônicos... Porto de Galinhas: ANPEd, 2012. 
Disponível em:

<http://35reuniao.anped.org.br/images/stories/trabalhos/GT15\%20Trabalhos/GT151837_int.pdf $>$. Acesso em: 20 out. 2019.

CAMPOS, Kátia Patrício Benevides; GLAT, Rosana. Procedimentos favoráveis ao desenvolvimento de uma criança com síndrome de down numa classe comum. Revista Educação Especial, Santa Maria, v.29, n.54, p.26-40, 2016. Disponível em: <https://periodicos.ufsm.br/educacaoespecial/article/view/10399>. Acesso em: 07 abr. 2019.

CARAMORI, Patricia Moralis; DALL'ACQUA, Maria Júlia Canazza. Estratégias pedagógicas empregadas por professores de educação especial aos seus alunos com deficiência intelectual severa: um estudo descritivo da prática docente. Revista Brasileira de Educação Especial, Marília, v.21, n.4, p.367-378, 2015. Disponível em:

<http://www.scielo.br/pdf/rbee/v21n4/1413-6538-rbee-21-04-00367.pdf>. Acesso em: 24 jun. 2019.

CARNEIRO. Maria Sylvia Cardoso. A deficiência intelectual como produção social: reflexões a partir da abordagem histórico-cultural. In: REUNIÃO ANUAL DA ANPED, 37, Florianópolis, 2015. Anais eletrônicos... Florianópolis: ANPEd, 2015. Disponível em: <http://37reuniao.anped.org.br/wp-content/uploads/2015/02/Trabalho-GT15-4079.pdf>. Acesso em: 07 jan. 2020.

CARNEIRO. Maria Sylvia Cardoso. O uso de métodos narrativos na pesquisa sobre a deficiência mental. In: REUNIÃO ANUAL DA ANPED, 29, Caxambu, 2006. Anais eletrônicos... Caxambu: ANPEd, 2006. Disponível em: < http://29reuniao.anped.org.br/trabalhos/trabalho/GT15-2342--Int.pdf >. Acesso em: 07 jan. 2020.

CHACON-ORTIZ, Manuel; CAMACHO-GUTIERREZ, Dulce; HEREDIA-ESCORZA, Yolanda. Conocimientos sobre aprendizaje móvil e integración de dispositivos móviles en docentes de la Universidad Nacional de Costa Rica. Revista Digital de Investigación en Docencia Universitaria, Lima, v.11, n.1, p.149-165, 2017. Disponível em: < http://www.scielo.org.pe/pdf/ridu/v11n1/a10v11n1.pdf>. Acesso em: 19 jan. 2019.

CUNHA, Roseane; ROSSATO, Maristela. A singularidade dos estudantes com deficiência intelectual frente ao modelo homogeneizado da escola: reflexões sobre o processo de inclusão. Revista Educação Especial, Santa Maria, v.28, n.53, p.649-664, 2015. Disponível em: 〈https://periodicos.ufsm.br/educacaoespecial/article/view/16288>. Acesso em: $11 \mathrm{abr}$. 2019.

DELGADO, Isabelle Cahino; BARBOSA, Talita Maria Monteiro Farias de; LIMA, Ivonaldo Leidson Barbosa; MATIAS, Wigna Raíssa Leite; ALVES, Giorvan Ânderson dos Santos. Perspectivas de letramento em sujeitos com déficit intelectual. Revista Prolíngua, v.10, n.1, 2015. Disponível em:

<https://periodicos.ufpb.br/index.php/prolingua/article/view/27600/14839>. Acesso em: 28 dez. 2019.

DELGADO, Isabelle Cahino; BARBOSA, Talita Maria Monteiro Farias de; MACÊDO, Bruna Samyres Oliveira de; LIMA, Cynderella Karla Moraes de; RÉGIS, Mariane Sousa; LIMA, Ivonaldo Leidson Barbosa; ALVES, Giorvan Ânderson dos Santos. Estratégias de 
letramento voltadas à intervenção fonoaudiológica em pessoas com síndrome de down. Revista Educação Especial, Santa Maria, v.32, n.1, p.33-49, 2019. Disponível em: <https://periodicos.ufsm.br/educacaoespecial/article/view/24631>. Acesso em: 07 jan. 2020.

EUZÉBIO, Michelle Donizeth; CERUTTI-RIZZATTI, Mary Elizabeth. Usos sociais da escrita: um estudo sobre práticas e eventos de letramento na vivência de professoras alfabetizadoras. Linguagem em (Dis)curso, Tubarão, v.13, n.1, p.13-34, 2013. Disponível em: 〈http://www.scielo.br/pdf/ld/v13n1/a02v13n1.pdf>. Acesso em: 11 nov. 2019.

FANTACINI, Renata Andrea Fernandes; DIAS, Tárcia Regina da Silveira. Professores do atendimento educacional especializado e a organização do ensino para o aluno com deficiência intelectual. Revista Brasileira de Educação Especial, Marília, v.21, n.1, p.5774, 2015. Disponível em: <http://www.scielo.br/pdf/rbee/v21n1/1413-6538-rbee-21-0100057.pdf>. Acesso em: 29 mar. 2019.

FERRI, Rita. Currículo e diferença: processos de seleção e organização de conhecimentos para atendimento educacional de alunos com histórico de deficiência mental. In: REUNIÃO ANUAL DA ANPED, 29, Caxambu, 2006. Anais eletrônicos... Caxambu: ANPEd, 2006. Disponível em: <http://29reuniao.anped.org.br/trabalhos/trabalho/GT15-2605--Int.pdf>. Acesso em: 07 jan. 2020.

FREITAS, Patrícia Martins de; RIBEIRO, Denise Oliveira. Neuroplasticidade na educação e reabilitação cognitiva da deficiência intelectual. Revista Educação Especial, Santa Maria, v.32, n.1, p. 59-89, 2019. Disponível em:

<https://periodicos.ufsm.br/educacaoespecial/article/view/31119>. Acesso em: 07 jan. 2020.

GALVÃO FILHO. Teófilo Alves. O desenvolvimento de projetos pedagógicos em ambiente computacional e telemático com alunos com paralisia cerebral. In: REUNIÃO ANUAL DA ANPED, 28, Caxambu, 2005. Anais eletrônicos... Caxambu: ANPEd, 2005. Disponível em: <http://www.galvaofilho.net/ANPEd_28_GalvaoFilho.pdf>. Acesso em: 18 dez. 2019.

GOMES, Adriana Leite Limaverde. A coerência textual de alunos com síndrome de down: uma análise da produção escrita através do uso de imagens. In: REUNIÃO ANUAL DA ANPED, 35, Porto de Galinhas, 2012. Anais eletrônicos... Porto de Galinhas: ANPEd, 2012. Disponível em:

<http://35reuniao.anped.org.br/images/stories/trabalhos/GT15\%20Trabalhos/GT152193_int.pdf>. Acesso em: 20 out. 2019.

GOMES, Adriana Leite Limaverde; FIGUEIREDO, Rita Vieira de. In: REUNIÃO ANUAL DA ANPED, 26, Poços de Caldas, 2003. Anais eletrônicos... Poços de Caldas: ANPEd, 2003. Disponível em:

<http://26reuniao.anped.org.br/trabalhos/adrianaleitelimaverdegomes.rtf >. Acesso em: 20 out. 2019.

HAQUIN, Dominique Manghi; CORNEJO, Fabiola Otarola; MOLINA, Marianela Arancibia. Adaptaciones metodológicas para el análisis del discurso de niños con discapacidad intelectual: narrando sin lenguaje. Signo y Pensamiento, Bogotá, v.35, n.69, p.68-82, 2016. Disponível em: <http://www.scielo.org.co/pdf/signo/v35n69/0120-4823-signo-35-6900068.pdf>. Acesso em: 19 out. 2019. 
HEIN, Julia Margarida; TEIXEIRA, Maria Cristina Triguero Veloz; SEABRA, Alessandra Gotuzo; MACEDO, Elizeu Coutinho de. Avaliação da eficácia do software "Alfabetização Fônica" para alunos com deficiência mental. Revista Brasileira de Educação Especial, Marília, v.16, n.1, p.65-82, 2010. Disponível em:

<http://www.scielo.br/pdf/rbee/v16n1/06.pdf>. Acesso em: 13 jan. 2020.

JORDAN, Monica; NOHAMA, Percy; BRITTO JUNIOR, Alceu de Souza. Software livre de produção textual com predição de palavras: um aliado do aluno especial. Revista Brasileira de Educação Especial, Marília, v.15, n.3, p.389-406, 2009. Disponível em: <http://www.scielo.br/pdf/rbee/v15n3/a04v15n3.pdf>. Acesso em: 15 dez. 2018.

JUTTEL; Flávia, KALEMPA; Vivian Cremer; PYKOSZ , Leandro Corrêa. Alfabetizando através da realidade aumentada: desenvolvimento de um aplicativo de auxílio à alfabetização utilizando a realidade aumentada para dispositivos móveis. Revista Tecnologias na

Educação, v.7, n.13, p. 01-11, 2015. Disponível em: <http://tecedu.pro.br/wpcontent/uploads/2015/12/Art-9-vol13-dez2015.pdf>. Acesso em: 17 abr. 2019.

LEMKE, Jay L.. Letramento metamidiático: transformando significados e mídias. Trabalhos em Linguística Aplicada, Campinas, v. 49, n.2, p.455-479, 2010. Disponível em: <http://www.scielo.br/pdf/tla/v49n2/09.pdf>. Acesso em: 20 ago. 2018.

LEONEL, Waléria Henrique dos Santos; LEONARDO, Nilza Sanches Tessaro. Concepções de professores da educação especial (APAEs) sobre a aprendizagem e desenvolvimento do aluno com deficiência intelectual: um estudo a partir da teoria vigotskiana. Revista Brasileira de Educação Especial, Marília, v.20, n.4, p.541-554, 2014. Disponível em: <http://www.scielo.br/pdf/rbee/v20n4/a06v20n4.pdf>. Acesso em: 09 ago. 2019.

LOPES, Esther; MARQUEZINE, Maria Cristina. Sala de recursos no processo de inclusão do aluno com deficiência intelectual na percepção dos professores. Revista Brasileira de

Educação Especial, Marília, v.18, n. 3, p. 487-506, 2012. Disponível em: <http://www.scielo.br/pdf/rbee/v18n3/a09.pdf>. Acesso em: 06 jan. 2020.

MACEDO, Maria do Socorro Alencar Nunes; ALMEIDA, Ana Caroline de; TIBÚRCIO, Ana Paula do Amaral. Práticas de alfabetização com crianças de seis anos no ensino fundamental: diferentes estratégias, diferentes concepções. Cadernos CEDES, Campinas, v.37, n.102, p.219-236, 2017. Disponível em: <http://www.scielo.br/pdf/ccedes/v37n102/1678-7110ccedes-37-102-00219.pdf>. Acesso em: 28 jul. 2019.

MAFFEZOL, Roberta Roncali; GÓES, Maria Cecília Rafael de. Jovens e adultos com deficiência mental: seus dizeres sobre o cenário cotidiano de suas relações pessoais e atividades. In: REUNIÃO ANUAL DA ANPED, 27, Caxambu, 2004. Anais eletrônicos... Caxambu: ANPEd, 2004. Disponível em: < http://www.anped.org.br/sites/default/files/t159.pdf >. Acesso em: 20 out. 2019.

MARTINEZ, Raidell Avello; DUART, Josep Maria. Nuevas tendencias de aprendizaje colaborativo en e-learning: claves para su implementación efectiva. Estudios Pedagógicos, Valdivia, v.42, n.1, p.271-282, 2016. Disponível em:

<http://scielo.conicyt.cl/pdf/estped/v42n1/art17.pdf>. Acesso em: 17 abr. 2019. 
MARTINS, Lígia Márcia; CARVALHO, Bruna; DANGIO, Meire Cristina Santos. O processo de alfabetização: da pré-história da escrita a escrita simbólica. Psicologia Escolar Educacional, Maringá, v.22, n.2, p.337-346, 2018. Disponível em: < http://www.scielo.br/pdf/pee/v22n2/2175-3539-pee-22-02-337.pdf >. Acesso em: 10 set. 2019.

MATURANA, Ana Paula Pacheco Moraes; MENDES, Enicéia Gonçalves. Inclusão e deficiência intelectual: escola especial e comum sob a óptica dos próprios alunos. Educar em Revista, Curitiba, n.66, p.209-226, 2017. Disponível em: <http://www.scielo.br/pdf/er/n66/0104-4060-er-66-209.pdf>. Acesso em: 17 nov. 2019.

MIRANDA, Theresinha Guimarães; ROSA, Dora Leal. As múltiplas dimensões educativas da escola para o aluno com deficiência mental. In: REUNIÃO ANUAL DA ANPED, 30, Caxambu, 2007. Anais eletrônicos... Caxambu: ANPEd, 2007. Disponível em: <http://www.anped.org.br/sites/default/files/gt15-3587-int.pdf>. Acesso em: 20 out. 2019.

MOLYNEUX, Paul; ALIANI, Renata. Texts, talk and technology: the literacy practices of bilingually-educated students. Trabalhos em Linguística Aplicada, Campinas, v.55, n.2, p.263-292, 2016. Disponível em: < http://www.scielo.br/pdf/tla/v55n2/0103-1813tla-55-02-00263.pdf>. Acesso em: 20 mar. 2019.

NÓBREGA-THERRIEN, Silvia Maria; THERRIEN, Jacques. Os trabalhos científicos e o estado da questão. Estudos em Avaliação Educacional, São Paulo, v. 15. n. 30, p. 5-16, 2004.

NÓBREGA-THERRIEN, Silvia Maria; THERRIEN, Jacques. O estado da questão: aportes teóricos-metodológicos e relatos de sua produção em trabalhos científicos In: FARIAS, Isabel Maria Sabino de; NUNES, Joao Batista Carvalho; NÓBREGA THERRIEN, Silvia Maria (Org.). Pesquisa científica para iniciantes: caminhando no labirinto. Fortaleza: EdUECE, 2010.

NEVES, Tânia Regina Levada; MENDES, Enicéia Gonçalves. Movimentos sociais e a autoadvocacia: analisando a participação de pessoas com deficiência mental. In: REUNIÃO ANUAL DA ANPED, 24, Caxambú, 2001. Anais eletrônicos... Caxambu: ANPEd, 2001. Disponível em: < http://24reuniao.anped.org.br/T1501262238875.doc>. Acesso em: 20 out. 2019.

OLEQUES, Liane Carvalho. Desenho e escrita: características na produção gráfica de duas crianças com síndrome de down. Revista Educação Especial, Santa Maria, v.29, n.54, Santa Maria, p.41-52, 2016. Disponível em:

<https://periodicos.ufsm.br/educacaoespecial/article/view/18141>. Acesso em: 07 abr. 2019.

PADILHA, Anna Maria Lunardi. A constituição do sujeito simbólico: para além dos limites impostos à deficiência mental. In: REUNIÃO ANUAL DA ANPED, 23, Caxambú, 2000. Anais eletrônicos... Caxambu: ANPEd, 2010. Disponível em: < http://23reuniao.anped.org.br/textos/1523t.PDF>. Acesso em: 03 mar. 2019.

PADILHA, Anna Maria Lunardi. Desenvolvimento psíquico e elaboração conceitual por alunos com deficiência intelectual na educação escolar. Revista Brasileira de Educação Especial, Marília, v.23, n.1, p. 9-20, 2017. Disponível em: 
<http://www.scielo.br/pdf/rbee/v23n1/1413-6538-rbee-23-01-0009.pdf >. Acesso em: 25 jan. 2019.

PEDRAZA MEDINA, Haydée; ACLE TOMASINI, Guadalupe.Formas de interacción y diálogo maestro-alumno con discapacidad intelectual en clases de español. Revista Mexicana de Investigación Educativa, México, v.14, n.41, p.431-449, 2009. Disponível em: <http://www.scielo.org.mx/pdf/rmie/v14n41/v14n41a5.pdf>. Acesso em: 02 jan. 2020.

PEDRO, Ketilin Mayra; CHACON, Miguel Claudio Moriel. Softwares educativos para alunos com Deficiência Intelectual: estratégias utilizadas. Revista Brasileira de Educação Especial, Marília, v. 19, n. 2, p. 195-210, 2013. Disponível em: <http://www.scielo.br/pdf/rbee/v19n2/a05v19n2.pdf>. Acesso em: 14 set. 2019.

PELOSI, Miryam Bonadiu; SILVA, Renata Mousinho Pereira da; SANTOS, Gladis dos; REIS, Nathalya Herzer. Atividades Lúdicas para o desenvolvimento da linguagem oral e escrita para crianças e adolescentes com síndrome de down. Revista Brasileira de Educação Especial, Marília, v.24, n.4, p.535-550, 2018. Disponível em:

<http://www.scielo.br/pdf/rbee/v24n4/1413-6538-rbee-24-04-0535.pdf>. Acesso em: 19 jan. 2020 .

PERTUZATTI, Ieda; DICKMANN, Ivo. Alfabetização e letramento nas políticas públicas: convergências e divergências com a Base Nacional Comum Curricular (BNCC). Ensaio: avaliação e Políticas Públicas em Educação, Rio de Janeiro, v.27, n.105, p.777-795, 2019. Disponível em:

<http://www.scielo.br/pdf/ensaio/v27n105/18094465ensaioS010440362019002701479.pdf>. Acesso em: 22 jan. 2020.

PINTO, Glaucia Uliana; CAMARGO, Evani Andreatta Amaral. A inter-relação entre a produção de sentidos e o aprendizado da escrita de uma criança com atrasos neste processo: um olhar a partir da perspectiva bakhtiniana. . In: REUNIÃO ANUAL DA ANPED, 37, Florianópolis, 2015. Anais eletrônicos... Florianópolis: ANPEd, 2015. Disponível em: < http://37reuniao.anped.org.br/wp-content/uploads/2015/02/Trabalho-GT15-3781.pdf > Acesso em: 07 jan. 2020.

PLETSCH, Márcia Denise; GLAT, Rosana. A escolarização de alunos com deficiência intelectual em diferentes contextos educacionais. In: REUNIÃO ANUAL DA ANPED, 34, Natal, 2011. Anais eletrônicos... Natal: ANPEd, 2011. Disponível em: http://34reuniao.anped.org.br/images/trabalhos/GT15/GT15-594\%20int.pdf >. Acesso em: 07 jan. 2020.

SANROMÀ-GIMÉNEZ, Mònica; LÁZARO-CANTABRANA, José Luis; GISBERTCERVERA, Mercè. La tecnología móvil. Una herramienta para la mejora de la inclusión digital de las personas con TEA. Psicología, Conocimiento y Sociedad, v.7, n.2, p.227-251, 2017. Disponível em: <http://www.scielo.edu.uy/pdf/pcs/v7n2/1688-7026-pcs-7-0200173.pdf>. Acesso em: 03 jan. 2020.

SANTOS, Teresa Cristina Coelho dos; MARTINS, Lúcia de Araújo Ramos. Práticas de Professores Frente ao Aluno com Deficiência Intelectual em Classe Regular. Revista Brasileira de Educação Especial, Marília, v.21, n.3, p.395-408, 2015. Disponível em: 
<http://www.scielo.br/pdf/rbee/v21n3/1413-6538-rbee-21-03-00395.pdf >. Acesso em: 29 jul. 2019.

SILVA; Glaucia Eunice Gonçalves da; OLIVEIRA, Ozerina Victor de; FERREIRA, Eucaris Joelma Rodrigues. Significados e sentidos na construção da identidade do deficiente intelectual para além de eufemismos. In: REUNIÃO ANUAL DA ANPED, 35, Porto de Galinhas, 2012. Anais eletrônicos... Porto de Galinhas: ANPEd, 2012. Disponível em: $<$ http://35reuniao.anped.org.br/images/stories/trabalhos/GT15\%20Trabalhos/GT152154_int.pdf>. Acesso em: 20 out. 2019.

SOUZA, Maria Imaculada de. O impacto da psicologia na construção histórica do conceito de deficiência mental. In: REUNIÃO ANUAL DA ANPED, 25, Caxambú, 2002. Anais eletrônicos... Caxambu: ANPEd, 2002. Disponível em: <http://25reuniao.anped.org.br/marciaimaculadasouzat15.rtf>. Acesso em: 20 out. 2019.

REINALDO, Francisco; MAGALHÃES, Demétrio; REIS, Luis Paulo; GAFFURI, Stefane; FREDDO, Ademir; HALLAL, Renato. Impasse aos desafios do uso de smartphones em sala de aula: investigação por grupos focais. RISTI, Porto, v.1, n.19, p. 77-92, 2016. Disponível em: <http://www.scielo.mec.pt/pdf/rist/n19/n19a07.pdf>. Acesso em: 13 out. 2019.

ROSSATO, Solange Marques; CONSTANTINO, Elizabeth Piemonte; MELLO, Suely Amaral. O ensino da escrita e o desenvolvimento das pessoas com deficiência intelectual. Psicologia em Estudo, Maringá, v.18, n. 4, p. 737-748, 2013. Disponível em: <http://www.scielo.br/pdf/pe/v18n4/15.pdf>. Acesso em: 07 out. 2019.

ROSSATO, Solange Pereira Marques; LEONARDO, Nilza Sanches Tessaro. A deficiência intelectual na concepção de educadores da Educação Especial: contribuições da psicologia histórico cultural. Revista Brasileira de Educação Especial, Marília, v.17, n.1, p.71-86, 2011. Disponível em: <http://www.scielo.br/pdf/rbee/v17n1/v17n1a06.pdf >. Acesso em: 14 jan. 2020.

SAITO, Fabiano Santos; RIBEIRO, Patrícia Nora de Souza. (Multi)letramento(s) digital(is) e teoria do posicionamento: análise das práticas discursivas de professoras que se relacionaram com as tecnologias da informação e comunicação no ensino público. Revista Brasileira de Linguística Aplicada, Belo Horizonte, v.13, n.1, p.37-66, 2013. Disponível em: < http://www.scielo.br/pdf/rbla/v13n1/aop1812.pdf>. Acesso em: 14 mar. 2019.

SÁNCHEZ-ALVAREZ, Jhon Fernando; ZAPATA-JARAMILLO, Carlos Mario; JIMÉNEZBUILES, Jovani Alberto. Heuristic assessment of software usability to facilitate computer use for people with motor disabilities. Revista EIA, v.14, n.27, 2017. Disponível em:

<https://revistas.eia.edu.co/index.php/Reveiaenglish/article/view/1205>. Acesso em: 08 out. 2019.

SANCHES-FERREIRA, Manuela; LOPES-DOS-SANTOS, Pedro; SANTOS, Miguel Augusto. A desconstrução do conceito de Deficiência Mental e a construção do conceito de Incapacidade Intelectual: de uma perspectiva estática a uma perspectiva dinâmica da funcionalidade. Revista Brasileira de Educação Especial, Marília, v.18, n. 4, p. 553-568, 2012. Disponível em: <http://www.scielo.br/pdf/rbee/v18n4/a02v18n4.pdf>. Acesso em: 11 ago. 2018. 
SANTAROSA, Lucila Maria Costi; CONFORTO, Débora. Tecnologias móveis na inclusão escolar e digital de estudantes com transtornos de espectro autista. Revista Brasileira de Educação Especial, Marília, v.21, n.4, p.349-366, 2015. Disponível em: < http://www.scielo.br/pdf/rbee/v21n4/1413-6538-rbee-21-04-00349.pdf>. Acesso em: 05 ago. 2018.

SANTOS, Daísy Cléia Oliveira dos. Potenciais dificuldades e facilidades na educação de alunos com deficiência intelectual. Educação e Pesquisa, São Paulo, v.38, n.4, p.935-948, 2012. Disponível em: <http://www.scielo.br/pdf/ep/v38n4/10.pdf>. Acesso em: 11 jan. 2020.

SCHIPPER, Carla Maria de; VESTENA, Carla Luciane Blum. Características do raciocínio do aluno deficiente intelectual à luz da Epistemologia Genética. Psicologia Escolar e Educacional, Maringá, v.20, n.1, p.79-88, 2016. Disponível em: http://www.scielo.br/pdf/pee/v20n1/2175-3539-pee-20-01-00079.pdf>. Acesso em: 13 ago. 2019.

SILVA, Fabiany de Cássia Tavares. Processos de ensino na educação dos deficientes mentais. In: REUNIÃO ANUAL DA ANPED, 23, Caxambú, 2000. Anais eletrônicos... Caxambu: ANPEd, 2010. Disponível em: http://23reuniao.anped.org.br/textos/1508t.PDF>. Acesso em: 09 jan. 2019.

SHIMAZAKI, Elsa Midori; AUADA, Viviane Gislaine Caetano; MENEGASSI, Renilson José; MORI, Nerli Nonato Ribeiro. O Trabalho com o gênero textual história em quadrinhos com alunos que possuem deficiência intelectual. Revista Brasileira de Educação Especial, Marília, v. 24, n.1, p.121-142, 2018. Disponível em: <http://www.scielo.br/pdf/rbee/v24n1/1413-6538-rbee-24-01-0121.pdf>. Acesso em: 06 abr. 2019.

SOARES, Magda. Novas práticas de leitura e escrita: letramento na cibercultura. Educação e Sociedade, Campinas, v.23, n.81, p.143-160, 2002. Disponível em: <http://www.scielo.br/pdf/es/v23n81/13935.pdf>. Acesso em: 28 out. 2019.

STREET, Brian Vicent. Políticas e práticas de letramento na Inglaterra: uma perspectiva de letramentos sociais como base para uma comparação com o Brasil. Cadernos CEDES, Campinas, v.33, n.89, p.51-71, 2013. Disponível em: <http://www.scielo.br/pdf/ccedes/v33n89/a04v33n89.pdf>. Acesso em: 29 set. 2018.

TASCA, Danieli Sebastiana Oliveira; GUEDES-PINTO, Ana Lúcia. A divulgação do conceito de letramento e o contexto da escola de nove anos: o que dizem as professoras alfabetizadoras? Cadernos CEDES, Campinas, v.33, n.90, p.257-276, 2013. Disponível em: <http://www.scielo.br/pdf/ccedes/v33n90/a06v33n90.pdf>. Acesso em: 07 abr. 2019.

TOLEDO, Elizabete Humai de; VITALIANO, Célia Regina. Formação de professores por meio de pesquisa colaborativa com vistas à inclusão de alunos com deficiência intelectual. Revista Brasileira de Educação Especial, Marília, v.18, n.2, p.319-336, 2012. Disponível em: <http://www.scielo.br/pdf/rbee/v18n2/v18n2a10.pdf>. Acesso em: 03 jan. 2020.

VIDEA, Rocío de los Angeles Peredo. Comprendiendo la discapacidad intelectual: datos, criterios y reflexiones. Revista de Psicologia, La Paz, n.15, p.101-122, 2016. Disponível em: <http://www.scielo.org.bo/pdf/rip/n15/n15_a07.pdf>. Acesso em: 14 ago. 2019. 
VIANA, Flávia Roldan; GOMES, Adriana Leite Limaverde. A produção escrita de pessoas com deficiência intelectual na interação com as tecnologias digitais da informação e comunicação. Revista Educação Especial, Santa Maria, v.30, n.58, p.297-312, 2017. Disponível em: <https://periodicos.ufsm.br/educacaoespecial/article/view/21931>. Acesso em: 07 abr. 2019.

VICTOR, Sonia Lopes. Aspectos presentes na brincadeira de faz-de-conta da criança com síndrome de down. In: REUNIÃO ANUAL DA ANPED, 24, Caxambú, 2001. Anais eletrônicos... Caxambu: ANPEd, 2001. Disponível em: <http://24reuniao.anped.org.br/T1542009135398.doc>. Acesso em: 11 jan. 2019.

VIVES, Estephanía Estupinan; PÉREZ, Diana Carolina Lopera; CARMONA, Cristián Andrés Díaz; GARCÍA, Ana Liliana Ríos; ÁLVAREZ, Libardo Reyes; SUAREZ, Eliana Rocío Peñaloza. ¿Cómo fomentar la integración de niños con discapacidad intelectual a través del juego? Diseño de un kit. Horizonte Sanitario, Villahermosa, v.16, n.2, p.121-126, 2017. Disponível em: http://www.scielo.org.mx/pdf/hs/v16n2/2007-7459-hs-16-02-00121.pdf>. Acesso em: 18 dez. 2019.

VOLTOLINI; Ana Graciela Mendes Fernandes da Fonseca. Programa Palma: dispositivos móveis e aplicativo como ferramenta para alfabetização. Aturá Revista Pan-Amazônica de Comunicação, Palmas, v.2, n.1, p.250-274, 2018. Disponível em:

<https://sistemas.uft.edu.br/periodicos/index.php/atura/article/view/4507/12539>. Acesso em: 22 nov. 2019.

\section{SOBRE AS AUTORAS:}

\section{Camila Almada Nunes}

Doutoranda em Educação pelo Programa de Pós-Graduação em Educação da Universidade Federal do Ceará (UFC); Integrante do Grupo de Pesquisa PRÓ-Inclusão; Bolsista de doutorado pela Coordenação de Aperfeiçoamento de Nível Superior (CAPES). E-mail: camilalmada@hotmail.com

(iD http://orcid.org/0000-0001-6000-5645

\section{Francisca Geny Lustosa}

Pós-doutoranda pelo programa de Pós-graduação em Educação da Universidade Estadual do Rio de Janeiro; Doutora em Educação pelo Programa de Pós-Graduação em Educação da Universidade Federal do Ceará (UFC); Docente do Curso de Pedagogia da Faculdade de Educação (FACED) da UFC e do Programa de Pós-Graduação em Educação da UFC; Coordenadora do Grupo de Pesquisa PRÓ-Inclusão; Membro da Comissão de Direitos Humanos da UFC e da Comissão de Direitos Humanos do Estado do Ceará. E-mail: franciscageny@yahoo.com.br

(iD) http://orcid.org/0000-0002-6143-9549 